\title{
Ground Shaking and Seismic Source Spectra for Large Earthquakes around the Megathrust Fault Offshore of Northeastern Honshu, Japan
}

\author{
by Lingling Ye, Thorne Lay, and Hiroo Kanamori
}

\begin{abstract}
Large earthquake ruptures on or near the plate boundary megathrust fault offshore of northeastern Honshu, Japan, produce variable levels of regional highfrequency ground shaking. Analyses of $0.1-10 \mathrm{~Hz}$ strong ground motion recordings from K-NET and KiK-net stations and $0.3-3.0 \mathrm{~Hz}$ short-period recordings from Hi-net stations establish that the shaking variations result from a combination of differences in seismic source spectra and path attenuation. Eleven earthquakes with $M_{\mathrm{w}} 6.0-7.6$ are analyzed, including interplate events at different positions on the megathrust within the rupture zone of the 11 March 2011 Tohoku $\left(M_{\mathrm{w}} 9.0\right)$ event and nearby intraplate events within the underthrusting Pacific slab. The relative ground shaking for frequencies of $5-10 \mathrm{~Hz}$ is strongest for the 7 April $2011\left(M_{\mathrm{w}} 7.2\right)$ intraslab event near the coast, followed by intraplate events beneath the outer-trench slope. Decreasing levels of high-frequency shaking are produced by interplate megathrust events moving from the down-dip edge of the seismogenic zone to the up-dip region near the trench. Differential attenuation measurements from averaged spectral ratios of strong-motion recordings indicate that average path attenuation is lower for events deeper on the megathrust or within the slab below the coast. Empirical Green's function analysis isolates the source spectra for the passband $0.3-3.0 \mathrm{~Hz}$, indicating higher corner frequencies for intraplate events and deep megathrust events than for shallow megathrust events. Similar differences in average source spectra are found for teleseismic $P$ waves. Depth-varying source radiation and path attenuation thus account for the high-frequency shaking for the 2011 Tohoku mainshock originating from the down-dip portion of the megathrust.
\end{abstract}

Online Material: Figures of spectral ratios, regression of averaged spectral ratios, and stacked spectral ratios.

Introduction

The 11 March $2011 M_{\mathrm{w}} 9.0$ Tohoku earthquake ruptured across the entire 200-km seismogenic width of the megathrust fault offshore of northeastern Honshu, producing strong ground motions in Japan and generating a devastating tsunami. Seismological, geodetic, and tsunami data indicate that seismic radiation characteristics varied over the fault surface. Concentrated sources of coherent short-period $P$-wave radiation to teleseismic distances (signal energy that has good phase alignment on a localized grid point when the teleseismic $P$ waves are backprojected to the source region) were located down-dip on the megathrust beneath the coastal environment (Ishii, 2011; Koper, Hutko, Lay, 2011; Koper, Hutko, Lay, et al., 2011; Meng et al., 2011; Wang and Mori, 2011; Yao et al., 2011), whereas very large slip with little coherent short-period radiation dominated in the up-dip portion of the megathrust from around the hypocenter to the Japan trench (Ammon et al., 2011; Fujii et al., 2011; Hayes, 2011; Ide et al., 2011; Iinuma et al., 2011; Ito et al., 2011; Koketsu et al., 2011; Lay, Ammon, Kanamori, Xue, et al., 2011; Lee et al., 2011; Maeda et al., 2011; Ozawa et al., 2011; Pollitz et al., 2011; Shao et al., 2011; Simons et al., 2011; Yagi and Fukahata, 2011; Yamazaki et al., 2011; Yokota et al., 2011; Yoshida et al., 2011; Yue and Lay, 2011). Analysis of strong-motion recordings by Kurahashi and Irikura (2011) also indicates that the down-dip region radiated the primary high-frequency energy observed in Japan, with a wide region onshore experiencing strong ground accelerations and moderately high ground velocities (Fig. 1). 

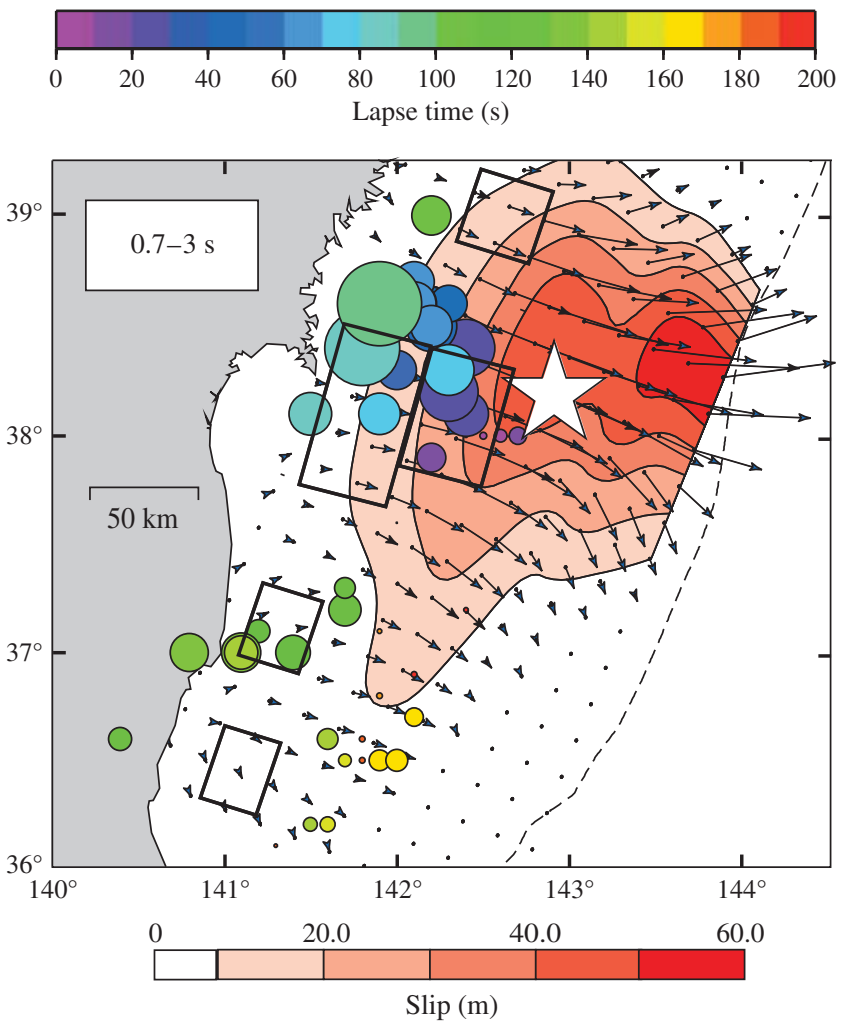

Figure 1. Rupture characteristics for the 11 March 2011 Tohoku earthquake. The coseismic slip distribution is from inversion of regional continuous GPS observations by Yue and Lay (2011). The vector orientations indicate the slip direction, and the vector magnitudes and contoured color scale indicate the total slip on each subfault. The white star indicates the epicentral location from Zhao et al. (2011). The position and timing of sources of coherent short-period teleseismic $P$-wave radiation in the passband imaged by backprojection of recordings at North American seismic stations, mainly from the EarthScope Transportable Array, are shown by the colored circles, with radius scaled proportional to relative beam power (Koper, Hutko, Lay, et al., 2011). The rectangles indicate estimated source locations of high-frequency strong ground motions determined by Kurahashi and Irikura (2011). Note that the regions with large slip locate up-dip, toward the trench (dashed line), whereas the coherent short-period radiation is from downdip, near the coastline.
The variation in seismic radiation from different portions of the rupture zone for the great 2011 Tohoku event may be the result of intrinsic differences in rupture behavior across the megathrust. Kanamori (1972) recognized that the shallowest part of the plate boundary megathrust just to the north of the 2011 event produced the great 1896 tsunami earthquake, with apparently long rupture duration and anomalously low short-period seismic-wave amplitudes. Estimates of moment-scaled rupture durations inferred from teleseismic $P$-wave data for moderate size $\left(M_{\mathrm{w}} \sim 5.8-6.8\right)$ events on the megathrust offshore of northeastern Honshu have alongstrike and along-dip variations, with a general tendency of decreasing moment-scaled duration as depth increases on the megathrust (Bilek and Lay, 1998; Lay and Bilek, 2007; Bilek et al., 2012). Systematic patterns as a function of depth in the seismic radiation spectra of great and moderate size events on the megathrusts in other subduction zones have also been observed. Lay et al. (2012) proposed a general megathrust rupture segmentation scenario with depthvarying domains $\mathrm{A}, \mathrm{B}$, and $\mathrm{C}$ (Fig. 2), based on a large suite of observations. Domain A extends across the shallowest $\sim 10-\mathrm{km}$-depth extent of the megathrust and hosts tsunami earthquake ruptures with low moment-scaled energy and weak short-period radiation such as the 1896 event; domain B spans the central portion of the megathrust over a depth range of $\sim 25 \mathrm{~km}$ with large coseismic slip but modest coherent short-period radiation; and domain $\mathrm{C}$ has smaller coseismic slip and strong coherent bursts of short-period radiation over the deepest $10-15-\mathrm{km}$-depth range of the seismogenic megathrust. Subduction zones with shallow dipping megathrusts and young subducting oceanic plates (southwest Japan, Cascadia, Mexico) appear to have an additional domain D at relatively shallow depths of 30-45 km, with slow slip events, low-frequency earthquakes, and seismic tremor. This transitional domain D may not exist down-dip of domain $\mathrm{C}$ in all regions; there is no indication of domain D behavior for the northeastern Honshu megathrust, which dips fairly steeply and involves a very old underthrusting Pacific plate.

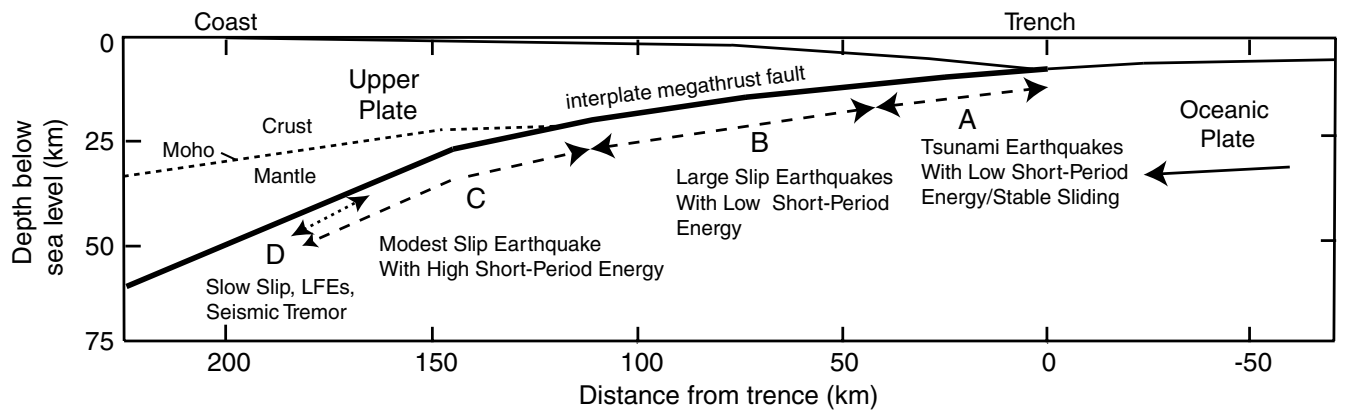

Figure 2. Schematic cross section of a generic interplate megathrust fault with four domains of depth-varying rupture characteristics: A, near-trench domain where tsunami earthquakes or anelastic deformation and stable sliding occur; B, central megathrust domain where large slip occurs with minor short-period seismic radiation; $\mathrm{C}$, down-dip domain where moderate slip occurs with significant coherent short-period seismic radiation; D, transitional domain, only present in some areas, typically with a young subducting plate, where slow slip events, lowfrequency earthquakes (LFEs), and seismic tremor can occur. (Modified from Lay et al. [2012]). 
The great 2011 Tohoku earthquake ruptured across the entire width of the megathrust, so domains $\mathrm{A}, \mathrm{B}$, and $\mathrm{C}$ appear to have failed in a single event. The spatial partitioning of high- and low-frequency seismic radiation from the rupture zone of such a great earthquake is difficult to resolve, so the conceptual model of megathrust rupture segmentation requires quantification by characterizing the overall source spectra of events that have ruptures confined to within each candidate domain. We address this for the source region of the 2011 Tohoku earthquake using regional and teleseismic data. This is still challenging because the frequencydependent attenuation structure is not known in detail. As a result, most studies of source spectrum variations across the megathrust have been restricted to frequencies $<2 \mathrm{~Hz}$ using teleseismic data (see summary in Lay et al. [2012]). We use regional data to extend the spectral bandwidth to $3-10 \mathrm{~Hz}$, thereby also connecting the megathrust rupture segmentation behavior to local ground-shaking effects and seismic hazard.

We also consider source spectrum variations between large events on the megathrust and nearby large intraplate events within the subducting slab. The intraplate events include shallow outer-trench slope normal-faulting events and deep thrust-faulting events below the megathrust near the coast. These commonly observed intraplate events are caused by large-scale deformation of the bending and sinking slab, influenced by temporally varying interplate stresses on the megathrust (Christensen and Ruff, 1988; Lay et al., 1989). Both types of intraplate events can produce stronger regional shaking relative to comparable seismic moment events on the megathrust, so they have particular seismichazard significance. Outer-rise normal-faulting events commonly radiate large-amplitude short-period seismic waves that generate strong shaking even though they are far offshore (Kanamori, 1971; Ammon et al., 2008; Hino et al., 2009; Lay, Ammon, Kanamori, Kim, et al., 2011). The intraslab earthquakes at depths of $\sim 40-100 \mathrm{~km}$ often lie below populated areas and can cause considerable damage to buildings because of high-frequency-rich strong ground motions with large peak ground accelerations, as were observed for the 15 January 1993 Kushiro-Oki $\left(M_{\mathrm{w}} 7.6\right)$ earthquake under Hokkaido (Morikawa and Sasatani, 2004), the 24 March 2001 Geiyo $\left(M_{\mathrm{w}}\right.$ 6.8) earthquake under southwestern Honshu (Miyatake et al., 2004; Kanamori et al., 2012), the 26 May 2003 Miyagi-Oki $\left(M_{\mathrm{w}} 7.0\right)$ earthquake under the Honshu coast (Tsuda et al., 2006), and the 23 July $2008\left(M_{\mathrm{w}} 6.8\right)$ northern Iwate, Japan, earthquake (Suzuki et al., 2009; Kanamori et al., 2012). It is well recognized that the strong ground shaking for intraplate events tends to be systematically higher amplitude than the ground motions from interplate events (Youngs et al., 1997; Si and Midorikawa, 1999; Purvance and Anderson, 2003), and this is commonly attributed to higher stress drops for intraplate events. Investigations of the frequency content of the ground shaking and source processes of events near the northeastern Japan megathrust are important both for understanding the variations in rupture process between intraplate and interplate faults and for considering the seismic hazard from all types of faulting near the megathrust.

Japan's extensive deployment since 1995 of highquality strong motion stations of K-NET and KiK-net and of the High Sensitivity Seismographic Network (Hi-net) provides superb data for investigating variations of frequency content of large earthquake ruptures on the Tohoku megathrust and nearby intraplate faults and relating the behavior to observations for the 2011 mainshock. We analyze the ground shaking and earthquake source spectra for 11 large $\left(M_{\mathrm{w}}\right.$ 6.0-7.6) earthquakes from 2003 to 2011 (Table 1), including a large thrust event $\left(M_{\mathrm{w}} 7.2,7\right.$ April 2011) that occurred in the Pacific slab below the down-dip limit of the 2011 Tohoku earthquake and an outer-rise normal-faulting event $\left(M_{\mathrm{w}}\right.$ 7.6, 11 March 2011) that occurred 40 min after the great 2011 event. Both events were probably triggered by stress changes resulting from the large fault slip in the great 2011 event (Lay, Ammon, Kanamori, Kim, et al., 2011; Ohta et al., 2011). Nakajima et al. (2011) suggest that the thrust event possibly involved reactivation of a preexisting hydrated fault with overpressurized fluids or serpentine minerals that had originally formed during bending near the trench. We also consider another outer-trench slope normal-faulting event $\left(M_{\mathrm{w}} 7.0,14\right.$ November 2005) and its preceding 2005 Miyagi-Oki interplate event ( $M_{\mathrm{w}}$ 7.3, 16 August 2005) located in the down-dip region of the megathrust, along with seven other underthrusting events located in megathrust domains A, B, or C. To suppress path effects, we use the empirical Green's function (EGF) method (Irikura, 1986), extracting reliable average source spectra that we can relate to the type of faulting and position along the megathrust. The characteristics of these large events are thus relevant to both basic earthquake source physics and regional seismic hazard.

\section{Ground-Shaking Analysis}

Reliable measurements of ground shaking for large earthquakes are of central importance for guiding appropriate building standards and proper design of critical facilities, such as nuclear power plants, located close to subduction zones. In this section, we examine spectral characteristics of ground motion induced by the large events in Figure 3, which are located on and around the rupture zone of the great 2011 Tohoku earthquake. We consider spectral ratios of ground motions relative to the large foreshock event on 9 March $2011\left(M_{\mathrm{w}}\right.$ 7.3) located near the hypocenter of the 2011 mainshock. This foreshock is located in domain B; we use it as a reference, as we are interested in relative levels of high-frequency ground motions produced as a function of depth of the source along the Tohoku megathrust and the relative frequency content of ground motions from megathrust versus intraslab faulting.

We use accelerometer recordings from the K-NET and KiK-net strong ground motion networks operated by the National Research Institute for Earth Science and Disaster Prevention (NIED), which provide many on-scale recordings 
Table 1

Event Information

\begin{tabular}{|c|c|c|c|c|c|c|c|c|}
\hline Number & $\begin{array}{c}\text { Event } \\
\text { (yyyy/mm/dd) }\end{array}$ & $\begin{array}{c}\text { Centroid Time* } \\
\text { (hh:mm:ss.ss) }\end{array}$ & $\begin{array}{l}\text { Longitude* } \\
\qquad\left({ }^{\circ} \mathrm{N}\right)\end{array}$ & $\begin{array}{l}\text { Latitude* } \\
\left({ }^{\circ} \mathrm{E}\right)\end{array}$ & $\begin{array}{l}\text { Depth* } \\
(\mathrm{km})\end{array}$ & $\begin{array}{c}\text { Magnitude* } \\
\left(M_{\mathrm{JMA}}\right)\end{array}$ & $\begin{array}{l}\text { Cut-off Frequency } \\
(\mathrm{Hz})\end{array}$ & $\begin{array}{l}\text { Rupture } \\
\text { Domain }\end{array}$ \\
\hline 1 & 2003-10-31 & 01:06:41.00 & 142.9790 & 37.8555 & 19 & 6.8 & - & B \\
\hline - & 2003-11-01 & $11: 24: 41.00$ & 142.7596 & 37.9219 & 24 & 3.8 & 4.0 & - \\
\hline - & 2003-11-05 & $00: 27: 23.00$ & 142.8120 & 37.9042 & 28 & 3.9 & 5.0 & - \\
\hline - & $2003-11-19$ & $10: 49: 41.00$ & 142.9150 & 37.7806 & 25 & 3.8 & 5.0 & - \\
\hline 2 & 2005-08-16* & $02: 46: 25.70$ & 142.2780 & 38.1500 & 42 & 7.2 & - & $\mathbf{C}$ \\
\hline- & 2004-11-07 & $18: 28: 46.00$ & 141.9120 & 38.3093 & 46 & 4.1 & 5.0 & - \\
\hline - & $2006-05-06$ & $11: 45: 43.00$ & 142.2240 & 38.4476 & 40 & 4.2 & 3.0 & - \\
\hline- & 2009-03-25 & 01:23:14.00 & 142.0270 & 38.2189 & 48 & 4.2 & 4.0 & - \\
\hline- & 2011-04-04 & $21: 52: 57.00$ & 141.9910 & 38.2976 & 52 & 4.2 & 2.0 & - \\
\hline - & 2011-04-19 & 03:02:52.00 & 141.8360 & 38.1597 & 57 & 4.0 & 2.0 & - \\
\hline - & 2011-04-26 & $04: 52: 21.00$ & 141.8667 & 38.3331 & 53 & 4.0 & 2.0 & - \\
\hline 3 & 2005-11-14* & 21:38:51.30 & 144.9450 & 38.0270 & 45 & 7.2 & - & (1) \\
\hline - & 2011-03-21 & $10: 43: 08.00$ & 144.8160 & 38.0613 & 9 & 4.6 & 3.0 & - \\
\hline- & 2011-03-27 & $14: 44: 25.00$ & 144.7700 & 38.0255 & 18 & 4.5 & 1.0 & - \\
\hline 4 & 2005-12-02 & 13:13:12.00 & 142.5730 & 38.0276 & 34 & 6.5 & - & B \\
\hline - & 2003-11-01 & $11: 24: 41.00$ & 142.7596 & 37.9219 & 24 & 3.8 & 3.0 & - \\
\hline- & 2003-11-04 & $15: 15: 40.00$ & 142.6650 & 37.8829 & 30 & 3.6 & 4.0 & - \\
\hline- & $2006-01-26$ & $16: 41: 31.00$ & 142.6720 & 38.0060 & 30 & 3.9 & 5.0 & - \\
\hline - & $2007-12-02$ & $15: 41: 50.00$ & 142.7030 & 37.9037 & 33 & 4.0 & 3.0 & - \\
\hline - & 2008-11-17 & $17: 27: 01.00$ & 142.6460 & 37.9837 & 28 & 4.1 & 2.0 & - \\
\hline - & $2010-04-02$ & $18: 32: 57.00$ & 142.6750 & 38.0069 & 30 & 4.1 & 2.0 & - \\
\hline 5 & 2008-07-19 & $02: 39: 35.00$ & 142.5460 & 37.5138 & 18 & 6.9 & - & B \\
\hline- & 2003-11-01 & 05:54:39.00 & 142.8664 & 37.4729 & 17 & 3.7 & 5.0 & - \\
\hline- & 2003-11-06 & $23: 55: 24.00$ & 142.7880 & 37.4759 & 22 & 3.7 & 5.0 & - \\
\hline- & $2005-12-20$ & $22: 44: 53.00$ & 142.5540 & 37.5132 & 24 & 4.0 & 3.0 & - \\
\hline- & $2008-02-11$ & $09: 31: 42.00$ & 142.7980 & 37.4625 & 17 & 4.0 & 3.0 & - \\
\hline- & 2009-09-03 & 05:29:17.00 & 142.6727 & 37.5596 & 28 & 3.7 & 5.0 & - \\
\hline 6 & 2010-03-14* & 17:08:04.10 & 141.8180 & 37.7240 & 39.8 & 6.7 & - & $\mathbf{C}$ \\
\hline- & $2004-08-23$ & $11: 48: 10.00$ & 141.8740 & 37.7544 & 43 & 4.2 & 3.0 & - \\
\hline- & $2007-10-11$ & $16: 19: 55.00$ & 141.9550 & 37.9106 & 45 & 3.9 & 3.0 & - \\
\hline- & $2007-10-23$ & $01: 22: 58.00$ & 141.7500 & 37.7012 & 45 & 4.0 & 3.0 & - \\
\hline- & $2010-05-12$ & 08:52:59.00 & 141.9800 & 37.9535 & 47 & 4.1 & 3.0 & - \\
\hline- & 2011-04-04 & $15: 47: 06.00$ & 141.5730 & 37.5818 & 49 & 4.1 & 3.0 & - \\
\hline 7 & 2011-03-09 & 02:45:32.00 & 143.0820 & 38.5372 & 19 & 7.3 & - & B \\
\hline 8 & 2011-03-09(1) & 21:22:10.00 & 143.6240 & 38.1150 & 32 & 6.0 & - & A or B \\
\hline 9 & 2011-03-09(2) & 21:24:08.00 & 143.0380 & 38.2203 & 25 & 6.4 & - & B \\
\hline - & 2003-09-08 & $21: 15: 59.00$ & 143.2530 & 38.5579 & 26 & 3.8 & 5.0 & - \\
\hline - & $2008-05-28$ & $20: 43: 33.00$ & 143.1946 & 38.5662 & 22 & 3.9 & 3.0 & - \\
\hline - & 2008-12-04 & $01: 42: 24.00$ & 143.2728 & 38.5131 & 23 & 4.2 & 2.0 & - \\
\hline- & $2008-12-04(1)$ & $18: 42: 05.00$ & 143.1360 & 38.5527 & 23 & 4.1 & 3.0 & - \\
\hline- & 2008-12-07 & $20: 39: 34.00$ & 143.2500 & 38.5438 & 27 & 4.2 & 3.0 & - \\
\hline- & 2009-02-03 & $15: 22: 49.00$ & 143.1856 & 38.4286 & 25 & 3.9 & 4.0 & - \\
\hline- & 2011-03-11 & 05:46:08.10 & 142.8610 & 38.1040 & 23.7 & 9.0 & - & $\mathbf{A} / \mathbf{B} / \mathbf{C}$ \\
\hline 10 & 2011-03-11(1) & 06:26:05.00 & 144.8980 & 38.1871 & 19 & 7.6 & - & (1) \\
\hline - & 2011-03-21 & 10:43:08.00 & 144.8160 & 38.0613 & 9 & 4.6 & 3.0 & - \\
\hline - & 2011-03-27 & $14: 44: 25.00$ & 144.7700 & 38.0255 & 18 & 4.5 & 1.0 & - \\
\hline 11 & 2011-04-07 & 14:32:50.00 & 142.1950 & 38.2478 & 57 & 7.2 & - & (2) \\
\hline- & $2004-11-07$ & $18: 28: 46.00$ & 141.9120 & 38.3093 & 46 & 4.1 & 5.0 & - \\
\hline - & $2006-05-06$ & $11: 45: 43.00$ & 142.2240 & 38.4476 & 40 & 4.2 & 3.0 & - \\
\hline - & $2009-03-25$ & $01: 23: 14.00$ & 142.0270 & 38.2189 & 48 & 4.2 & 4.0 & - \\
\hline - & 2011-04-04 & $21: 52: 57.00$ & 141.9910 & 38.2976 & 52 & 4.2 & 2.0 & - \\
\hline - & 2011-04-11 & $21: 03: 37.00$ & 141.9620 & 38.4233 & 58 & 4.2 & 2.0 & - \\
\hline - & 2011-04-18 & $10: 56: 05.00$ & 142.0010 & 38.4951 & 54 & 4.2 & 2.0 & - \\
\hline- & 2011-04-19 & 03:02:52.00 & 141.8360 & 38.1597 & 57 & 4.0 & 2.0 & - \\
\hline- & $2011-04-26$ & $04: 52: 21.00$ & 141.8667 & 38.3331 & 53 & 4.0 & 2.0 & - \\
\hline
\end{tabular}

*The origin time, location, and magnitude come from the GCMT catalog for event 2005-08-16, 2005-11-14, and 2010-03-14, while for other events this information comes from the regional CMT catalog (Asano et al., 2011). Events numbered from 1 to 11 highlighted with bold text are large events, followed by from 2 to 8 small events used as EGFs in the source spectra analysis. 

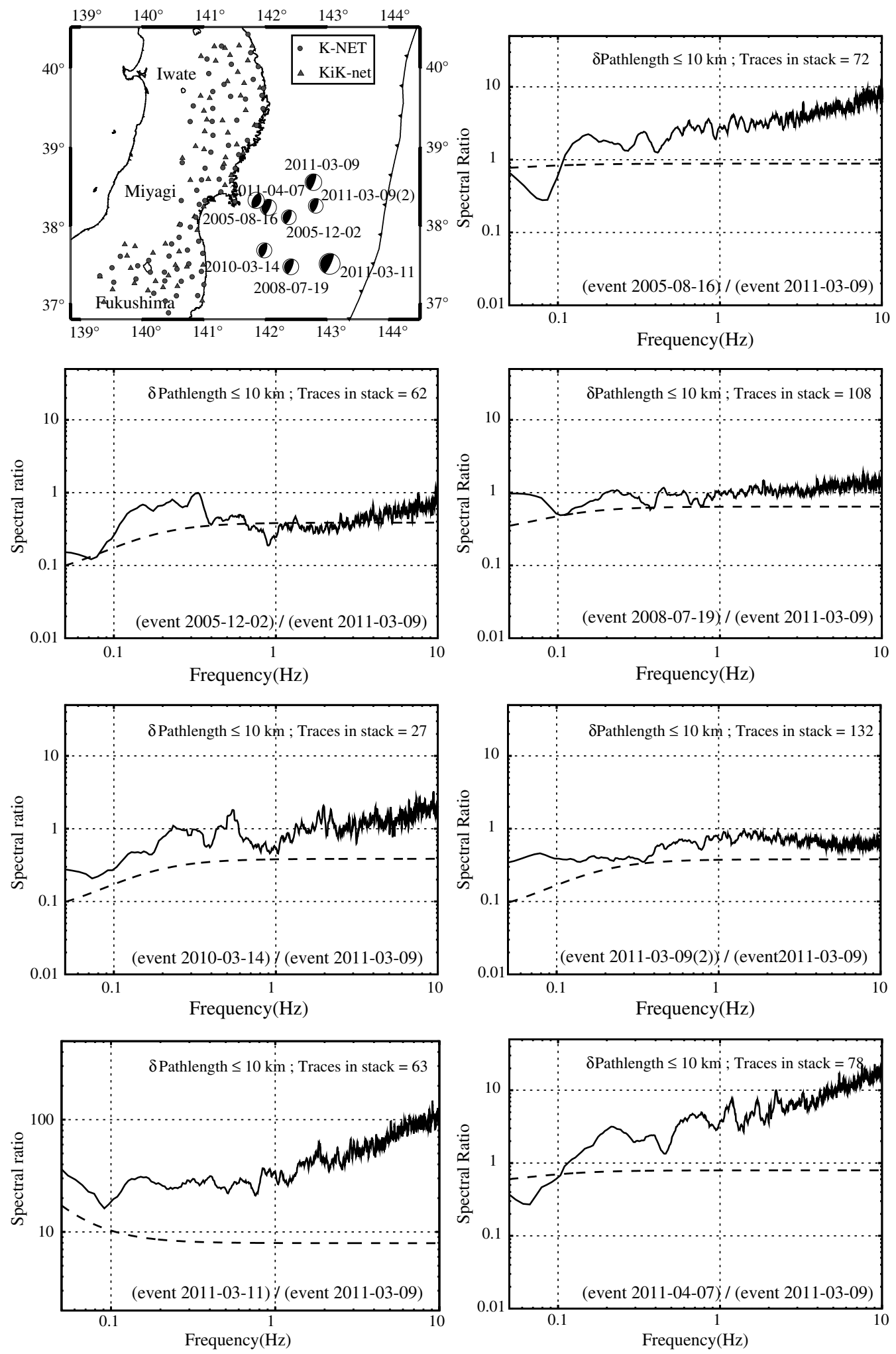

Figure 3. Stacked spectral ratios of ground accelerations for large events in the Japan subduction zone around Tohoku relative to the foreshock on 9 March 2011 ( $M_{\mathrm{w}}$ 7.3, event 2011-03-09) being the reference event (denominator) in each case. Subsets of K-NET and KiK-net strong-motion sensors in Iwate, Miyagi, and Fukushima prefectures (map) with common path lengths between sources and receiver (within $10 \mathrm{~km}$ ) are used. The stacked, smoothed spectral ratios from all three components 100-s-long signals for the indicated number of channels are shown. The dashed curves are predicted spectral ratios for reference Brune $\omega^{-2}$ source models for a 3-MPa constant stress drop and the regional centroid moment tensor (CMT) seismic moments. The barbed solid curve in the map indicates the position of the trench. (Event numbers: yyyy-mm-dd.) 
for each of the large regional events. We restrict our analysis to the closest stations, located in Iwate, Miyagi, and Fukushima Prefectures (Fig. 3). The KiK-net stations have threecomponent dual surface/borehole accelerometers, while K-NET stations are all located at the surface. The borehole records provide higher signal-to-noise ratios with less influence of site effects, particularly nonlinear effects that can occur for surface sensors with particularly strong shaking for stations on either low-velocity or high-velocity materials (Tsuda et al., 2006; Assimaki et al., 2008). Our approach involves computing spectral ratios of recordings for two events at the same station, component by component, with emphasis on frequencies in the passband $0.1-10.0 \mathrm{~Hz}$. Spectral ratios cancel out the instrument responses and site effects, to the degree that they do not vary rapidly with back azimuth or due to nonlinearity. The individual spectral ratios for all stations and components are averaged to give the spectral ratio for each event relative to the foreshock.

We initially computed average ratios of spectra for complete, 100-s-long ground motions for all common station components for each event relative to the 9 March 2011 foreshock (event 2011-03-09). We find systematic spatial trends, with relatively high spectral ratios for events near the coast and in the outer rise (Fig. 3). There is no significant difference between the event-averaged spectral ratios calculated separately for data from KiK-borehole observations, KiK-surface observations, and K-NET surface observations below $10 \mathrm{~Hz}$. (E) Figs. S1-S8 in the electronic supplement compare the average ratios for stations in each azimuthally distinct prefecture for each instrument type.) This indicates negligible contributions to the averaged ratios from any nonlinearity in the site responses within our passband for the modest range of large earthquake size considered in this section, so the ratios in Figure 3 combine all types of sensors. Given that the spectral ratios are influenced by multiple factors such as relative source spectra, relative geometric spreading factors, relative radiation pattern factors, and relative path attenuation, we include in the average spectral ratio stacks in Figure 3 only those ratios for which the hypocenter-toreceiver direct-line path lengths from the numerator event are within $10 \mathrm{~km}$ of the path lengths from the denominator (reference) event. Requiring common path lengths for each ratio restricts the azimuthal sampling and reduces the effects of geometric spreading differences and common attenuation effects (as for a uniform $Q$ model), so the ratios can be viewed as direct measures of relative ground shaking referenced to the foreshock event. This restriction to common path lengths mainly affects the baselines of the ratios, but the frequencydependent trends of the ratios remain similar to those for the ratios of all data grouped by prefecture shown in (E) Figures S1-S8 in the electronic supplement.

We use the Global Centroid Moment Tensor (GCMT) centroid locations for each event to compute the sourcereceiver distances, recognizing that these centroid estimates may have some absolute bias, but it is likely to be in common for the full set of events considered here because they are relatively close together and have similar size and mechanisms. Similar results are found using Japan Meteorological Agency (JMA) hypocenters or regional centroid moment tensor (CMT) centroids obtained by NIED or Asano et al. (2011), although the specific groups of stations that are included can vary (the subset of stations used in the equal path length stacks for each event in Fig. 3 are indicated in the corresponding (E) Figs. S1-S8 in the electronic supplement). The individual spectra were smoothed with an 11-sample running mean, and the spectral ratios were averaged over all components to give the spectral ratios extending to $10 \mathrm{~Hz}$ as shown in Figure 3 . The numbers of channels used for averaging are from 60 to 130 with the exception of just 27 channels for event 2010-03-14, which is located furthest away from the reference event 2011-03-09. The constraint to similar path lengths within $10 \mathrm{~km}$ eliminated all stations for outer-rise events, but those will be considered below; spectral ratios for all strong-motion observations are shown for the 2011-03-11 (1) outer-rise event in (E) Fig. S7 in the electronic supplement.

To provide a consistent reference source spectrum behavior, we use an omega-square spectrum, $\dot{M}(f)$, given by

$$
\hat{\dot{M}}(f)=\frac{M_{0} f_{c}^{2}}{f^{2}+f_{c}^{2}},
$$

where $M_{0}, f(\omega=2 \pi f)$, and $f_{c}$ are the seismic moment, frequency (angular frequency), and the corner frequency, respectively, given by

$$
f_{c}=c \beta\left(\frac{\Delta \sigma}{M_{0}}\right)^{1 / 3} .
$$

Here $\beta, \Delta \sigma$, and $c$ are the shear-wave velocity, a stress parameter, and a constant, respectively. This is the form introduced by Brune (1970) to explain the $S$-wave radiation. The constant $c$ is 0.49 if all the quantities are given in SI units. In the context of our study, $\Delta \sigma$ is just a scaling parameter (Boore, 1983) and is not necessarily meant to be the stress drop at the source. The stress drop of an earthquake can be defined unambiguously if it is spatially uniform. However, the stress drop in real earthquakes is most likely spatially very complex and cannot be defined in a simple way. In this paper we use the term "stress drop" for the stress parameter $\Delta \sigma$ in equation (2). The stress parameter does not necessarily equate to the stress drop of the source; but for purposes of qualitative interpretations, we use $\Delta \sigma$ as a rough approximation of the source stress drop. In our reference spectrum, we use $\beta=3.75 \mathrm{~km} / \mathrm{s}$ and $\Delta \sigma=3 \mathrm{MPa}$. The predicted spectral ratios for each event pair, assuming these parameters are constant, are shown by dashed lines in Figure 3.

The common path-length average spectral ratios in Figure 3 indicate that overall ground shaking has systematic variation with event position on the megathrust, as is indicated by the average ratios of all data in each prefecture (E) Figs. S1-S8 in the electronic supplement). The spectral ratios for events 2005-12-02, 2008-07-19, and 2011-03-09 (2), all located in domain B near the reference event 2011-03-09, are quite consistent with predictions for the 


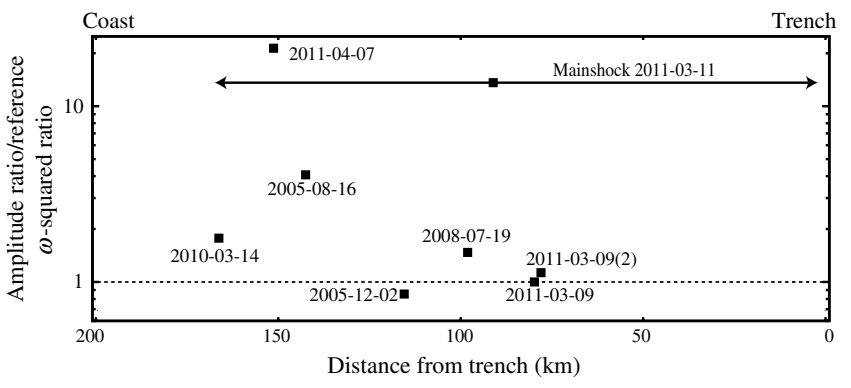

Figure 4. The 10-Hz spectral ratio amplitudes for large events around the Tohoku megathrust relative to the foreshock (event 2011-03-09) normalized by spectral ratios for the Brune $\omega^{-2}$ source models, plotted as a function of perpendicular distance from the trench to the JMA source locations.

Brune $\omega^{-2}$ source models. This does not mean the assumption of a 3-MPa stress drop is correct, but there is at least relative consistency in ground-shaking spectra produced by nearby ruptures within the central megathrust domain. The ground-shaking spectral ratios show a rapid increase in amplitude with increasing frequency from 0.1 to $10 \mathrm{~Hz}$ for the Miyagi-Oki 2005-08-16 event in domain C, the mainshock (event 2011-03-11, which ruptured domains A, B, and C), and the 2011-04-07 intraslab event, all relative to the reference domain $\mathrm{B}$ event.

Figure 4 shows variation of average spectral ratio amplitudes at $10 \mathrm{~Hz}$ for these total ground-shaking measurements (from Fig. 3) relative to the reference $\omega^{-2}$ source model spectral ratios, as a function of distance of each event's JMA location from the trench. Along the megathrust, relatively larger ground shaking is produced by events 200508-16 and 2010-03-14, which are in the down-dip (domain C) portion of the megathrust, and there is no systematic highfrequency ground-shaking enhancement for up-dip events 2005-12-02, 2008-07-19, and 2011-03-09(2) near the reference domain B event 2011-03-09. Relatively high-frequency ground shaking was produced by the 2011 Tohoku mainshock, which ruptured across the entire width of the megathrust as indicated by the line with arrows. It is plausible that the short-period content in the mainshock signals originates primarily from the down-dip region of the fault, as suggested by the location of subsources of strong ground motion energy radiation inferred by Kurahashi and Irikura (2011). These spectral variations are a combined effect of source radiation and path attenuation differences but directly indicate that large near-coast events on the down-dip part on the megathrust produce a factor of 2 to 4 stronger $10-\mathrm{Hz}$ ground shaking on Honshu. This tendency of increasing highfrequency shaking from up-dip region to down-dip region along the megathrust could be accounted for by using distance-from-trench ground-shaking predictions for offshore megathrust events, given the geometry of the subduction zone, such as that shown in Figure 4.

The average spectral ratio of intraplate event 2011-04-07 is significantly larger at high frequencies (Fig. 3). The normalized spectral ratio of this event at $10 \mathrm{~Hz}$ (Fig. 4) is 23 times larger than that for the reference domain B event 2011-03-09 and $\sim 5$ times larger than that for the nearby domain $\mathrm{C}$ interplate event 2005-08-16. Strong short-period radiation has also been observed from large intraslab earthquakes (the 1993 Kushiro-Oki and 1994 Hokkaido Toho-Oki earthquakes) along the southern Kurile-Hokkaido arc by Morikawa and Sasatani (2003), and the source rupture process on those events shows that the observed high-frequency-rich ground motion is due to the short duration rupture over a small source area with high stress drop (Morikawa and Sasatani, 2004). Because there are significant differences in the propagation paths and the focal mechanisms between the intraplate event 2011-04-07 and the interplate event 2011-03-09, we cannot yet directly attribute the difference to the source properties, but from the earthquake hazard perspective, the ground shaking from the intraslab event at intermediate depth clearly poses significantly greater hazard for large events. This is supported by comparison with the relative spectra for the 2011 Tohoku mainshock (Figs. 3 and 4). At approximately common propagation distances, the $M_{\mathrm{w}} 7.2$ intraplate event produced about twice as high average ground shaking at $10 \mathrm{~Hz}$ compared with the $M_{\mathrm{w}} 9.0$ mainshock (Fig. 4). Because distance from the mainshock is ambiguous, direct comparisons at common stations are perhaps more meaningful, but even in that case, the amplitudes of shaking from the intraplate event are about $30 \%-50 \%$ of those for the great event despite their large difference in seismic moment (E) Figs. S6 and S8 in the electronic supplement).

The complete ground-motion spectra for 100-s-long time windows capture total ground-shaking behavior, but clearly multiple seismic phases are included in those windows, with the high-frequency signal being dominated by shear-wave energy. While those measurements allow us to include the mainshock spectra for comparison, for the shorter rupture duration $M_{\mathrm{w}} \sim 7.0$ events we can measure the spectra for specific $P$ and $S$ time windows to evaluate any differences in ground shaking for different phases and for measuring overall relative attenuation differences. We manually picked the arrival times of $P$ and $S$ waves and calculated the $P$ spectral ratios for vertical components for the interval from a few seconds before the $P$ arrival to the arrival time of the $S$ wave. For $S$ and $S H$ spectral ratios, we use 30-s time windows beginning just before the $S$ arrivals using three components and tangential components, respectively. The spectral ratios were again made relative to the corresponding signals for the 9 March foreshock (event 2011-03-09; Fig. 5), for stations with distance differences of less than $10 \mathrm{~km}$ for each event pair. The isolated phase spectral ratios are not calculated for the 2011 Tohoku event because of the long source duration and ambiguity of $S$-wave onsets. The behavior of the isolated phase spectral ratios is very similar to what was found for the total ground-shaking spectra. Figure 5 shows that the $P, S$, and $S H$ spectra all have similar frequency enrichment for intraplate event 2011-04-07 and domain C events 2005-08-06 and 2010-03-14, with clear distinction from the other three domain B events. 

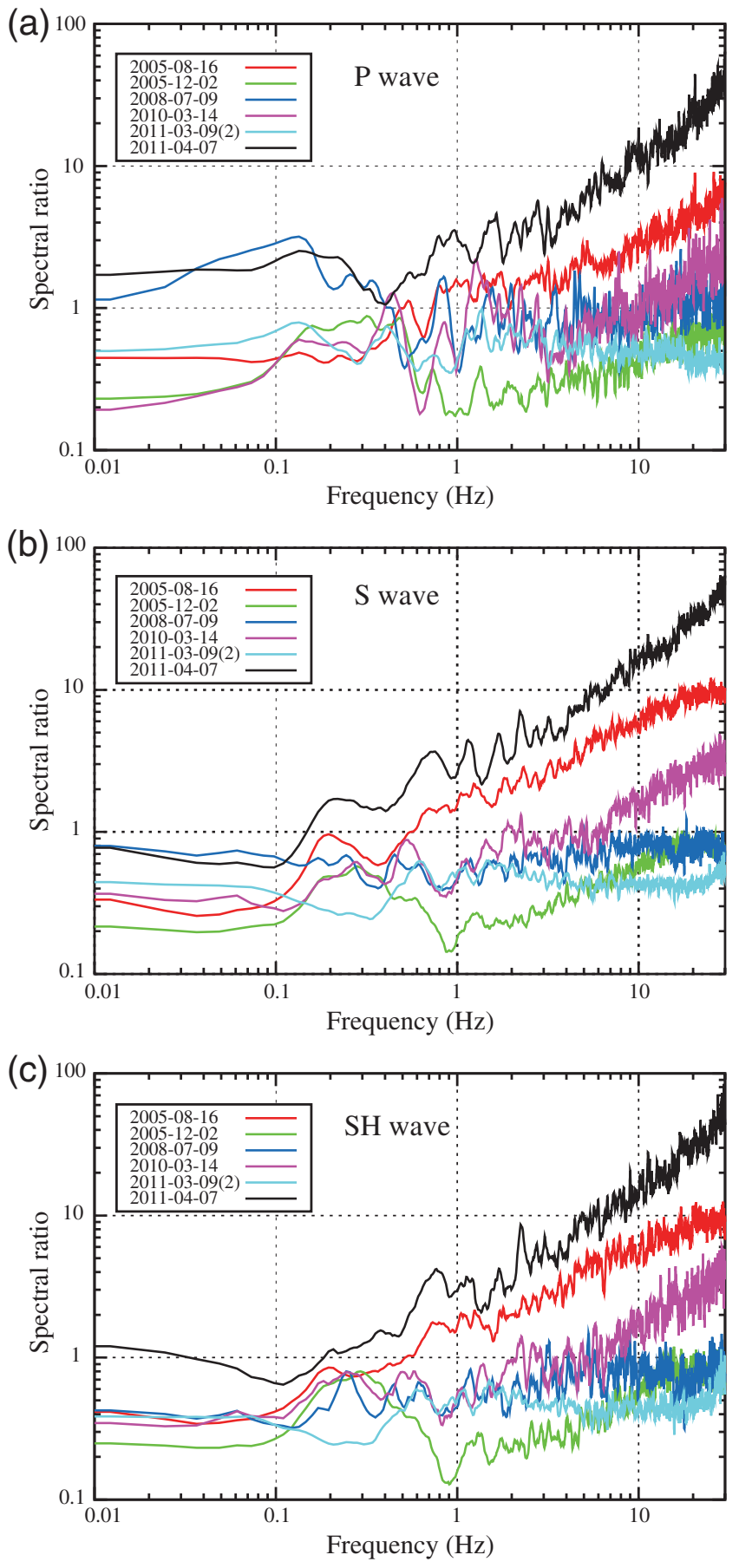

Figure 5. Stacked $P, S$, and $S H$ ground acceleration spectral ratios for large events relative to the foreshock (event 2011-03-09) for the same K-NET and KiK-net strong-motion data used in Figure 3. Only event station pairs with path-length difference within $10 \mathrm{~km}$ of each other are used. The time window for $P$ spectral ratios is from the arrival time of the $P$ wave to the arrival time of the $S$ wave, and only vertical components are used; 30 -s time windows after the arrival time of the $S$ wave are used for calculating $S$ - and $S H$-wave spectra using three components and tangential components, respectively.

The log-log spectral ratio plots in Figures 3 and 5 show some characteristic upward curvature of the spectral ratios suggestive of differential attenuation relative to reference event 2011-03-09. These spectral ratio trends can result from combined effects of differential path attenuation and differential source spectral shape (Purvance and Anderson, 2003). To provide a first-order quantification of the size of possible differential attenuation effects, we assume that the spectral shape differences are negligible (later we will show that this is actually not the case for the intraplate events) and use a simple convolution model for the ground motions to estimate average differential attenuation affecting frequencies out to $10 \mathrm{~Hz}$ :

$$
\ln \left[\frac{U(f)}{U_{\mathrm{ref}}(f)}\right]=\ln \left[\frac{S(f) R^{\mathrm{pt}} G(f) R(f) I(f)}{S_{\mathrm{ref}}(f) R_{\mathrm{ref}}^{\mathrm{pt}} G_{\mathrm{ref}}(f) R_{\mathrm{ref}}(f) I_{\mathrm{ref}}(f)} \frac{e^{-\pi f t^{*}}}{e^{-\pi f t_{\mathrm{ref}}^{*}}}\right],
$$

where $U(f)$ is the ground motion; $S(f)$ is the source function; $R^{\mathrm{pt}}$ is an average radiation pattern term for the signal in the time window; $G(f)$ is the elastic propagation effect; $R(f)$ is the receiver site response effect; $I(f)$ is the instrument response; and $t^{*}=$ travel time $/ Q$, where the quality factor $Q$ is assumed to be independent of frequency $f$ for frequencies less than $10 \mathrm{~Hz}$. The assumption of constant $Q$ may not be valid for many of the spectral ratios extending to higher frequencies; our goal here is not to characterize detailed path attenuation parameters (which should be done on a pathby-path basis rather than for an aggregate spectral ratio measure), but to give a first-order parameterization of the magnitude of differential attenuation that could account for the linear slopes of the event-averaged spectral ratios below $10 \mathrm{~Hz}$. The reference event parameters are represented by the subscript ref. We assume that the instrument response and site response terms cancel quite precisely for each component ratio and that the elastic propagation terms cancel to first order for geometric spreading and overall amplitude of energy flux over the equal path lengths despite the differences in actual paths for each ratio. The source terms are assumed to have the $\omega$-square model form of equation (1), for which the ratios are expected to flatten to a constant beyond the corner frequency of the smaller event in the pair, as indicated by the predicted ratios for 3-MPa stress-drop models in Figure 3. The differential attenuation $\Delta t^{*}=t^{*}-$ $t_{\text {ref }}^{*}$ can then be estimated over the high-frequency portion of the spectral ratio to the extent that it behaves linearly (as expected for a constant $Q$ situation). We measured $\Delta t^{*}$ by least-squares linear regression of the natural $\log$ spectral ratios across the linear frequency band $0.3-10.0 \mathrm{~Hz}$, over which roughly linear relationships are observed, solving for both slope and intercept of the regression curve. The intercept is allowed to vary to accommodate the uncertainties in precise seismic moments, stress drops, and geometric spreading factors, which shift the ratios up or down.

The $\Delta t^{*}$ estimates for the total ground-motion ratios and the $P, S$, and $S H$ ratios relative to the reference event 2011-03-09 are listed in Table 2. Corresponding regressions are shown in (E) Figures S9-S12 in the electronic supplement. For frequencies higher than $10 \mathrm{~Hz}$, the spectral ratios 
Table 2

$\Delta t^{*}$ from Spectral Ratios in Figures 3 and 5

\begin{tabular}{crrrc}
\hline Event $(\mathrm{yyyy} / \mathrm{mm} / \mathrm{dd})$ & $\Delta t_{100 \mathrm{~s}}^{*}(\mathrm{~s})$ & \multicolumn{1}{c}{$\Delta t_{P}^{*}(\mathrm{~s})$} & \multicolumn{1}{c}{$\Delta t_{S}^{*}(\mathrm{~s})$} & \multicolumn{1}{c}{$\Delta t_{S H}^{*}(\mathrm{~s})$} \\
\hline $2005-08-16$ & -0.0457 & -0.0306 & -0.0525 & -0.0502 \\
$2005-12-02$ & -0.0280 & -0.0126 & -0.0327 & -0.0300 \\
$2008-07-19$ & -0.0159 & 0.0003 & -0.0151 & -0.0165 \\
$2010-03-14$ & -0.0314 & -0.0126 & -0.0348 & -0.0344 \\
$2011-03-09(2)$ & 0.0057 & 0.0067 & 0.0055 & 0.0040 \\
$2011-03-11$ & -0.0445 & - & - & - \\
$2011-04-07$ & -0.0572 & -0.0588 & -0.0640 & -0.0606
\end{tabular}

$\Delta t^{*}$ is measured for the passband $0.3-10.0 \mathrm{~Hz}$ relative to the event 2011-03-09. $\Delta t_{100 \mathrm{~s}}^{*}$ is calculated by fitting the three-component averaged spectral ratios in Figure 3 for 100 -s-long signals, and $\Delta t_{P}^{*}$, $\Delta t_{S}^{*}$, and $\Delta t_{S H}^{*}$ are calculated from the spectral ratios of $P$ waves, three-component $S$ waves, and $S H$ waves in Figure 5, respectively.

begin to flatten and appear to be dominated by noise (or possibly frequency dependence of $Q$ ). The differential attenuation measurements indicate that average path attenuation is lower for events deeper on the megathrust $\left(\Delta t^{*} \sim-0.03\right.$ to $-0.05 \mathrm{~s})$ and within the slab below the coast $\left(\Delta t^{*} \sim\right.$ $-0.06 \mathrm{~s})$, while the differential attenuation is smaller $\left(\Delta t^{*} \sim\right.$ 0.0 to $0.03 \mathrm{~s}$ ) for the three events in the up-dip region of the Tohoku megathrust close to the reference event. Outer-rise event 2011-03-11(1) has a negative differential attenuation as well, as indicated by positive slope of the spectral ratio (E) Fig. S7 in the electronic supplement), which suggests that the paths dive into the high-velocity, high- $Q$ slab rather than traversing the sedimentary wedge. When the differential attenuation is larger, the values for the 100-s-long total ground shaking are closer to those for the $S$ waves, as expected. While we do not believe nonlinear effects are significant in the averaged spectral ratios, they would likely have greater effect for the $S$-wave measures and for the events closer to the coast, possibly giving some variation between $P$ and $S$ behavior.

Because the data used in the stacked spectral ratios come from a moderate range of paths (tending to be nearby stations in one prefecture or another due to the equal propagation distance requirement; see (E) Figs. S1-S8 in the electronic supplement), these differential attenuation estimates provide only an estimate of the average relative attenuation for the large events around the megathrust on paths to the mainland for frequencies less than $10 \mathrm{~Hz}$, under the assumption that source spectral differences are negligible. We emphasize that these differential attenuation measures are provided to indicate the likelihood of systematic variations in attenuation, not as robust measures of the medium properties. The enhancement in high-frequency spectra is clearly partly the result of differences in attenuation caused by three-dimensional $Q$ distribution (because the path lengths are similar, the $Q$ must increase for the paths from events near the coast). Thus, part of the trend seen in Figure 4 is caused by systematic differences in attenuation due to heterogeneous $Q$ structure varying with distance from the coast. However, the baseline shifts in the spectral ratios in Figures 3 and 5 relative to the refer- ence model indicate that not all of the differences are due to attenuation variations. One could use the estimated differential attenuation values to measure the source spectrum differences; however, because of the averaging involved, this is not very precise and requires the assumption that all spectra fall off as $\omega^{-2}$. In the next section, we will suppress the individual path effects using the EGF method with several small events near each large event to extract reliable average source spectra free of that assumption.

\section{Source Spectra Analysis}

Ground motions produced by an earthquake depend on the event source properties, including seismic source spectrum and focal mechanism; propagation effects, including geometric spreading, scattering due to the lateral heterogeneities and anelasticity along the propagation path; and near-surface site amplification effects due to the shallow geological layers beneath the station. The propagation and site effects are very difficult to model for high frequencies, and the EGF method is designed to isolate the source spectrum effects for a large earthquake using records of nearby small earthquakes recorded at the same station. We apply this method to estimate the source spectra of the large megathrust and intraslab events around the 2011 Tohoku rupture zone.

The EGF method is very dependent on the selection of small events, which should be nearly co-located with the large event, have the same focal mechanism, and have a large difference in corner frequency, which requires a large difference in seismic moment, while still having good signal-tonoise ratio over substantial bandwidth. For offshore events, this is usually difficult to achieve, due to the long paths involved and low signal levels from small events near the large earthquakes. For the KiK-net and K-NET strong ground motion recordings, small events located near to the large earthquakes considered here tend to be poorly recorded except for events close to the coast (where attenuation is relatively low, as we have seen). Thus, we primarily use data from Hi-net (operated by NIED). This is one of the finest arrays in the world, and each station is equipped with a borehole shortperiod instrument typically deployed about $100 \mathrm{~m}$ below the surface to suppress surface noise, enabling high gain recording of high-quality seismograms for low-magnitude events offshore at many of the same stations for which the large events produce on-scale records. The use of Hi-net borehole data also insures the EGF method will not be affected by nonlinear site responses that sometimes exist for surface sensors when weak motions are compared with strong motions ( $\mathrm{Si}$ and Midorikawa, 1999; Tsuda et al., 2006; Assimaki et al., 2008).

Eleven large $\left(M_{\mathrm{w}} 6.0-7.6\right)$ earthquakes, including three intraslab events and eight interplate events around the Tohoku megathrust from 2003 to 2011 are analyzed using recordings for both the large and small events at the same station. Average spectral ratios for the large events relative to the reference foreshock for $P, S$, and $S H$ phases are shown in (E) Figure S13 in the electronic supplement. Most of our 
EGF events have JMA magnitudes $M_{\mathrm{JMA}} \sim 4.0$, which is about as small as viable while retaining good signal bandwidth. We use the focal mechanisms, centroid locations, and seismic moment determinations from a revised (relative to NIED rapid determinations) regional CMT catalog (Asano et al., 2011), which is based on waveform inversion of seismograms from regional Hi-net and broadband F-net stations. For each large event, we have collected data from two to eight nearby EGF events with $M_{\text {JMA }} 3.8-4.2$, except for the distant outer-rise events 2005-11-14 and 2011-03-11(1) for which the EGF magnitudes are a bit larger $\left(M_{\mathrm{JMA}} \sim 4.5-4.6\right)$. High-quality strong ground motion data from KiK-net borehole and a few K-NET stations for near-shore events 200508-16 and 2011-04-07; a few of their corresponding small EGF events are included, but we did not find many useful strong-motion records for the small events further offshore. The strong-motion spectral ratios are very consistent with those for the Hi-net data for the same and other EGF events over the $0.3-3.0 \mathrm{~Hz}$ passband, and we are confident that this subset of data also has no nonlinear behavior of significance. Table 1 lists the regional CMT event information for the EGF events used for each large earthquake.

The locations, magnitudes, and focal mechanisms of the 11 large earthquakes and their EGF events and the stations used are shown in Figure 6. The calculations of $P, S$, and $S H$ spectral ratios between the large events and the EGF events use the same windowing as described in the GroundShaking Analysis section, with all ratios for a given EGF event being averaged for each phase. We then shifted the event-averaged spectral ratios according to the CMT seismic moment of each EGF event to a common reference EGF moment level corresponding to $M_{\mathrm{w}} 4.0$. For intraplate event 2011-04-07, the number of EGFs with focal mechanisms matching the mainshock is limited, so we shifted each EGFaverage spectral ratio first relative to the EGF event 2011-0411 (which has the most favorable focal mechanism) by leastsquares fitting the spectral ratios from 0.3 to $3 \mathrm{~Hz}$ and then shifting all the curves to the reference moment level of $M_{\mathrm{w}}$ 4.0. These moment-corrected spectra are shown in Figure 7, with each curve being for a different EGF event. The degree to which the curves overlap indicates the relative consistency of the CMT seismic moment estimates. The ratios of the 3-MPa constant stress drop $\omega^{-2}$ reference spectrum for each large event to that of an $M_{\mathrm{w}} 4.0$ event are shown as reference. For that stress drop, the predicted flattening of the spectral ratios caused by the corner frequency of the EGF event (denominator) is expected to initiate at about $2.5 \mathrm{~Hz}$. Because our EGF magnitudes vary somewhat and the stress drops may differ from $3 \mathrm{MPa}$, some ratios indicate flattening at higher frequency or lower frequency, although noise levels clearly increase above $3 \mathrm{~Hz}$. At low frequency (below $\sim 0.3 \mathrm{~Hz}$ ), the limited bandwidth of the instruments and the weak long-period wave excitation for the small events lead to a flattening of the ratios. Thus, the reliable bandwidth over which we can estimate the source spectra is limited to the range $0.3-3.0 \mathrm{~Hz}$, which is above the corner frequency for all of the large events. Nonetheless, we obtain stable estimates of the source spectra over this range of frequencies in each case.

We identified the high-frequency limit for each EGFcorrected average spectrum before the onset of the flattening effect caused by the small event corner frequency based on linearity of the spectral decay to that point and used these as cutoff frequencies for each case (listed in Table 1). We then averaged the EGF-corrected source spectra for each large event over the varying bandwidth provided by each EGF event (essentially extending the bandwidth at high frequency when smaller EGF events were available). The final $P, S$, and $S H$ source spectra estimates for the 11 events are shown in Figure 8. The spectra below $0.3 \mathrm{~Hz}$ are not reliably estimated. These spectra should now be free of any contribution from site effects, path attenuation, geometric spreading, focal mechanism, or instrument response. The absolute amplitudes are relative to the seismic moment of the $M_{\mathrm{w}} 4.0$ reference event $\left(M_{0}=1.26 \times 10^{15} \mathrm{~N} \cdot \mathrm{m}\right)$. The dashed curves for the ratio of the $\omega^{-2}$ reference spectrum with a constant $3-\mathrm{MPa}$ stress drop provide a common reference, with most spectra on or above that reference. It appears that the estimated source spectra fall off linearly to $3 \mathrm{~Hz}$, indicating that they are free of bias from the EGF corner frequency, except for the outer-trench slope event spectra (2005-11-14 and 2011-0311[1]) for which the larger EGF events had to be used. The spectra in those cases may be valid only below $2 \mathrm{~Hz}$. In general, the spectral decay slope is -2 or less, with the slopes appearing to be somewhat less for 2005-08-16 and 2010-0314 (the two domain C events), 2005-11-14 and 2011-03-11 (1) (the two trench-slope intraplate events), and 2011-04-07 (the intraslab thrust event).

To facilitate comparison with the strong-motion spectral ratios described in the preceding section, we compute spectral ratios of the event average source spectra relative to the reference foreshock 2011-03-09, along with the corresponding spectral ratios for the constant stress-drop models and show these in Figure 9. The $S$ and $S H$ ratios tend to track quite closely, and they differ from $P$ spectra only for the 2005-11-14, 2011-03-11(1), and 2011-04-07 events. The ratios are flatter than seen in Figures 3 and 5 as a result of the explicit correction for attenuation and radiation pattern effects, but there are still systematic variations in absolute level; for the 2005-08-16 and 2011-04-07 events there are clear differences in slope over the spectral range 0.3-3.0 Hz. The $P$-wave spectra for the trench slope events (2005-11-14 and 2011-03-11[1]) are high relative to the 3-MPa model, as are the spectra for the domain C 2010-03-14 event. The other events have relatively flat spectra, but the levels are low for events 2003-10-31, 2005-12-02, 2008-07-19, and 2011-0309(1), suggestive of lower stress drop than for the reference event. The overall differences in spectra in Figure 9 can mostly be interpreted as departures from constant stress drop $\omega^{-2}$ source variations.

Interpretation of spectral ratios provides limited resolution of the absolute spectra, but we can at least estimate 

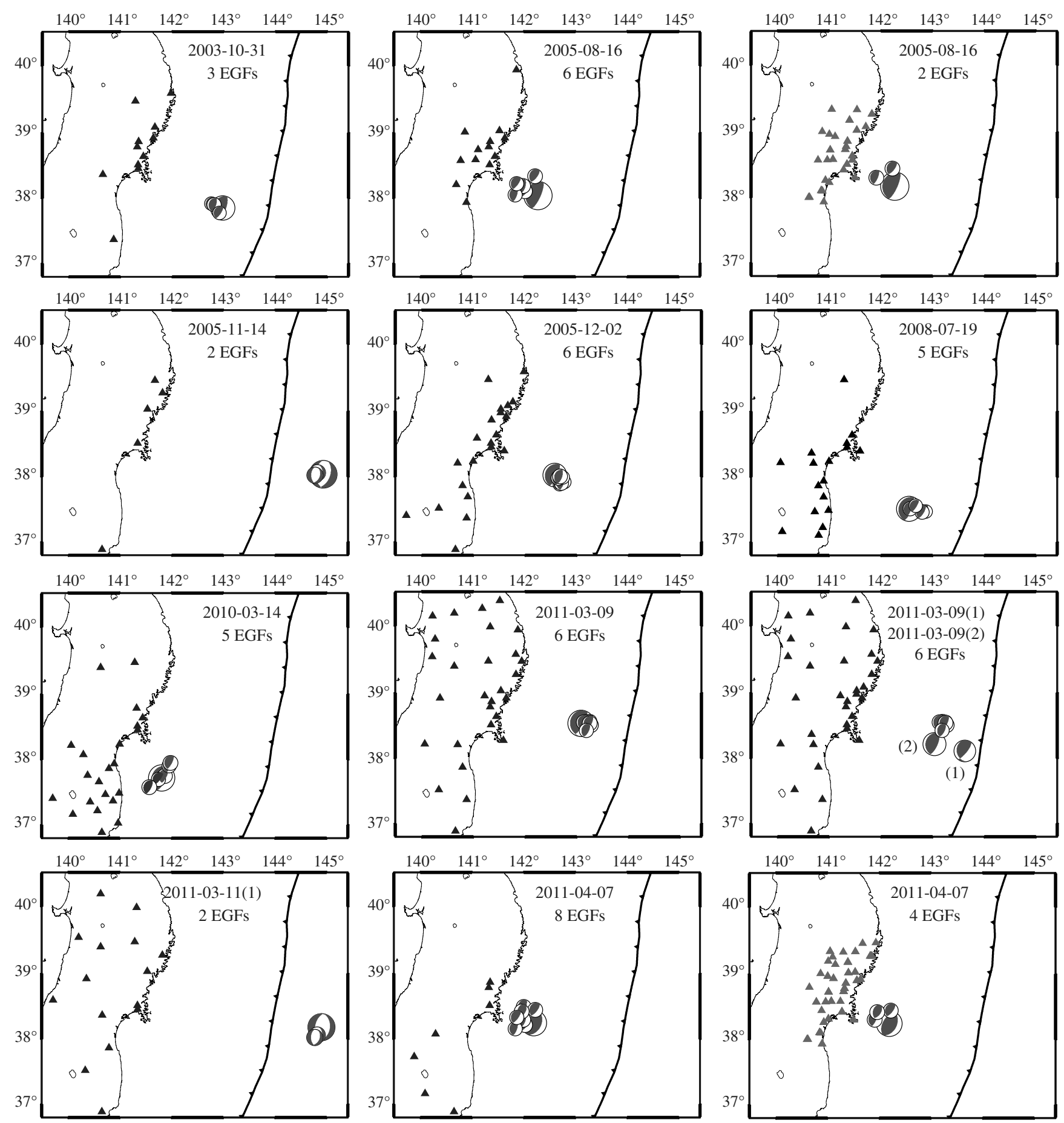

Figure 6. Focal mechanisms of the large events around the Tohoku megathrust with from two to eight nearby small events used as empirical Green's functions to correct for path effects on each path to regional seismic stations. Focal mechanisms are mainly from a regional CMT catalog (Asano et al., 2011), although GCMT solutions are used for events 2005-08-16, 2005-11-14, and 2010-03-14, which are not in the regional catalog. The triangles show the stations with large event and EGF recordings, with black symbols for Hi-net stations and the gray symbols for K-NET and KiK-net borehole stations (2005-8-16 and 2011-04-07 events only). The barbed solid curves indicate the position of the trench.

differences in stress drop and high-frequency falloff rate, because the EGF-corrected spectra are presumably free of site, path, and radiation pattern effects. To give a sense for the level of stress-drop variations that are involved, we fit the spectral ratios with theoretical spectra assuming reference event 2011-03-09 has a 3-MPa stress drop and a standard $\omega^{-2}$ spectral decay. We then varied the stress-drop parameter and, if necessary, the spectral decay of the numerator event to roughly match the overall level and shape of the observed source spectral ratios around $0.3-3 \mathrm{~Hz}$. The high-frequency 

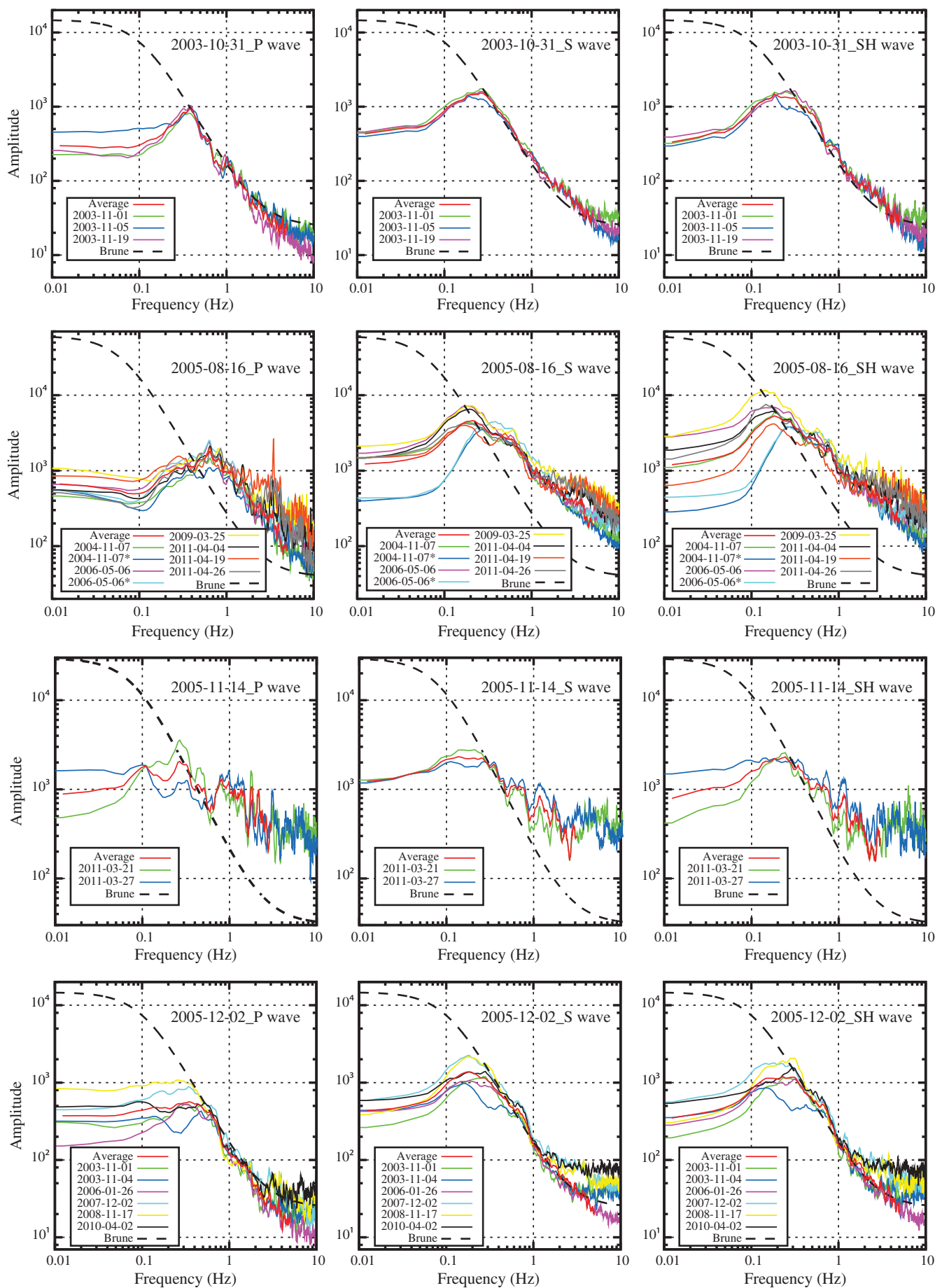

Figure 7. $\quad P, S$, and $S H$ source spectra determined using the EGF spectral ratio method. Each curve is the stacked spectral ratio of the large event relative to the indicated EGF event for all stations with data as shown in Figure 6 . The data time windows and components are the same as in Figure 5. The asterisks indicate data from the K-NET and KiK-net (borehole), with all others being from Hi-net. The red curves are the average source spectra computed from the stacked EGF spectra for frequencies up to the cutoffs indicated in Table 1, which is where the EGF corner frequency begins to flatten the spectral ratios. The dashed curves are predicted source spectral ratios for the reference Brune $\omega^{-2}$ source models relative to an $M_{\mathrm{w}} 4.0$ event, with a 3-MPa constant stress drop and the regional CMT seismic moments (GCMT moments are used for events 2005-08-16, 2005-11-14, and 2010-03-14). The source spectra are reliable from about 0.3 to $3.0 \mathrm{~Hz}$ in each case. (Continued)

enhancement in spectral ratios of down-dip events on the megathrust and intraslab events and the anomalous spectral slope of event 2011-04-07 are of primary interest here. We keep the shear velocity constant in the calculations.
The estimates from fitting the spectral ratios are shown in Figure 10. The estimated stress parameters are $\sim 1.5-2.0$ times higher for down-dip events 2005-08-16 and 2010-0314 and $\sim 2.0-4.0$ times higher for outer-rise normal-faulting 

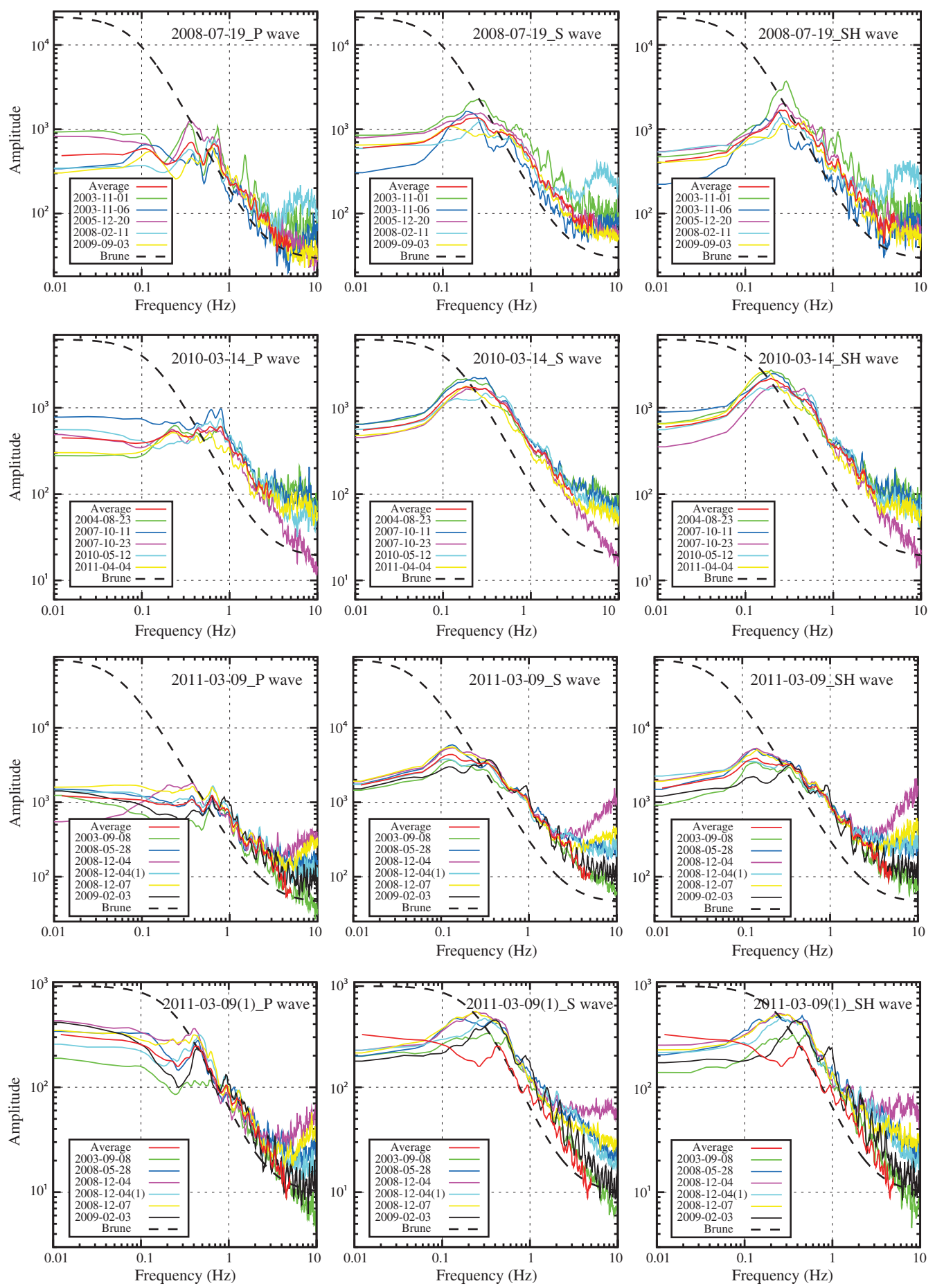

Figure 7. Continued.

events 2005-11-14 and 2011-03-11(1), relative to the reference foreshock 2011-03-09 in domain B. This general behavior is consistent with the factor of $2-5$ difference in stress drops estimated between populations of interplate and intraplate events globally (Allmann and Shearer, 2009; Iwata and Asano, 2011) and with source spectra in the Mexico subduction zone (Purvance and Anderson, 2003), another region with long-term dense strong ground motion recordings.
While variations in stress drop are not unexpected within any single faulting domain, the higher stress drop for event 2011-03-11(1) relative to the nearby event 2005-11-14 may possibly be influenced by large stress perturbations associated with the great 2011 mainshock. The difference of $P$ and $S$ spectral ratios between the two outer-rise events could be due to the $P$ waves having a higher corner frequency than $S$ waves as predicted for the quasidynamic circular crack 

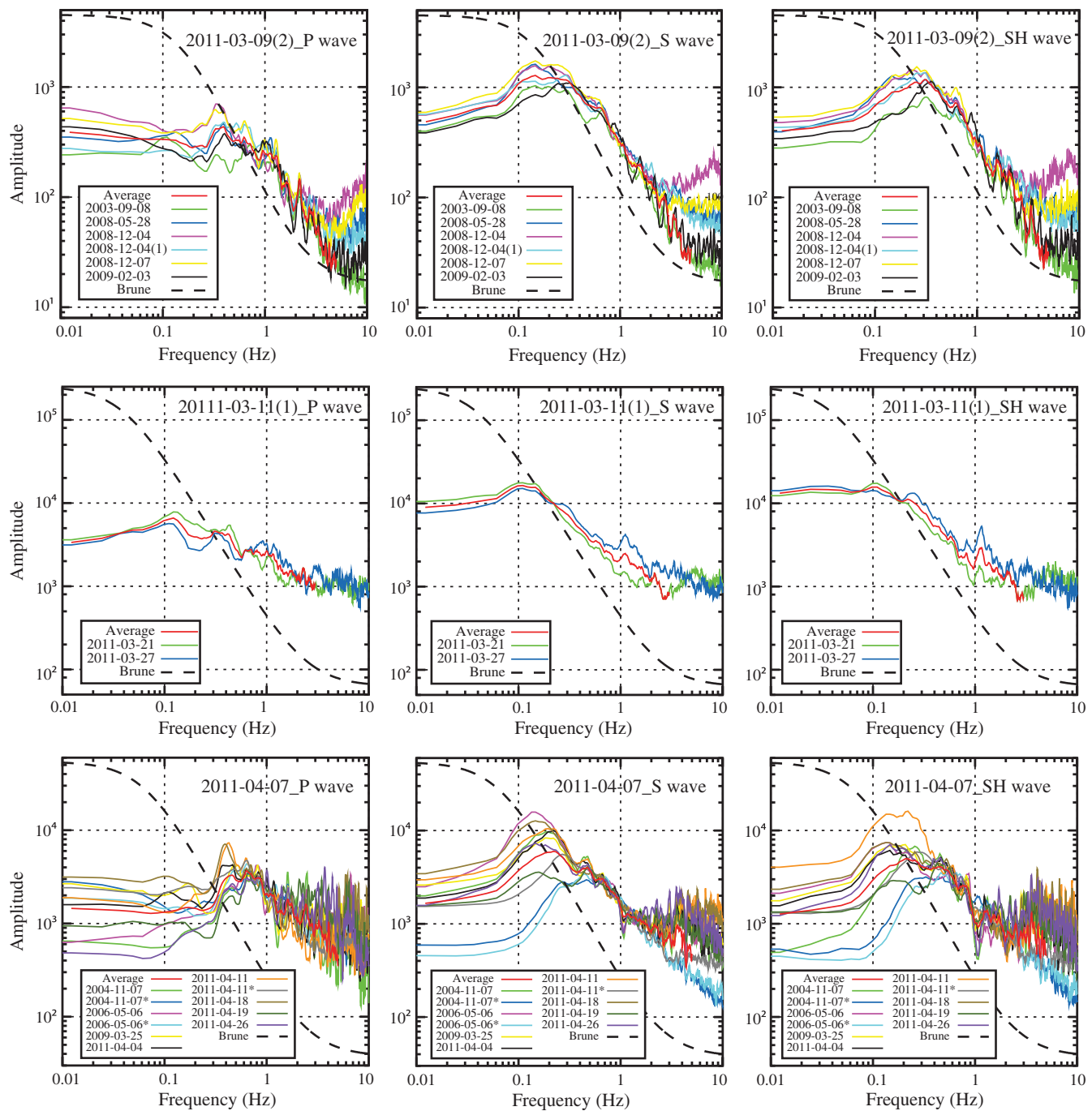

Figure 7. Continued.

model (Madariaga, 1976). The data are too limited to justify very detailed analysis, and the main result is the tendency to have a factor of 2-3 higher stress-drop parameter for the intraplate and down-dip megathrust events relative to the domain $\mathrm{B}$ events.

Intraslab event 2011-04-07 has the most anomalous source spectra (Figs. 8 and 9) and the most negative $\Delta t^{*}$ (Table 2), which combine to give the large ground-shaking difference for this event (Figs. 3-5). The shape of the spectral ratio in Figure 9 cannot be matched just by difference in stress drop, even for very large $(>100 \mathrm{MPa})$ stress drops that give extreme shifts of the corner frequency of the event. Figures 10e,f explores predictions of the spectral ratio for this event for $\omega^{-n}$ models with $n$ ranging from 1.5 to 2.0, for stress drops of 4 and $7.5 \mathrm{MPa}$. For $n \sim 1.6$ or $\sim 1.8$ with a stress drop of 7.5 MPa, good fits of the spectral ratios of this event relative to foreshock 2011-03-09 are found for $P$ waves and $S / S H$ waves, respectively. With the spectral decay rate exponent being lower than -2 , the negative $\Delta t^{*}$ values in Table 2 are likely overestimates, as there is trade-off in the source spectrum decay rate and the differential attenuation estimation.

Given the limited bandwidth over which we can reliably resolve the source spectra and the modest size of the overall data set, we view these stress-drop parameters and spectral slope estimates as good only to the first order and provide them mainly to quantify the magnitude of variations involved, not to provide absolute measures with high fidelity. However, the isolated source spectra for these large events do indicate systematic variations of source radiation properties along the megathrust and significant highfrequency radiation from the intraslab events, which may result from local frictional differences on the fault surface and/or different stress drops. This information is more quantitative than that obtained by backprojection methods, which resolve only the spatially coherent part of shortperiod signals without establishing the overall spectral levels involved. 

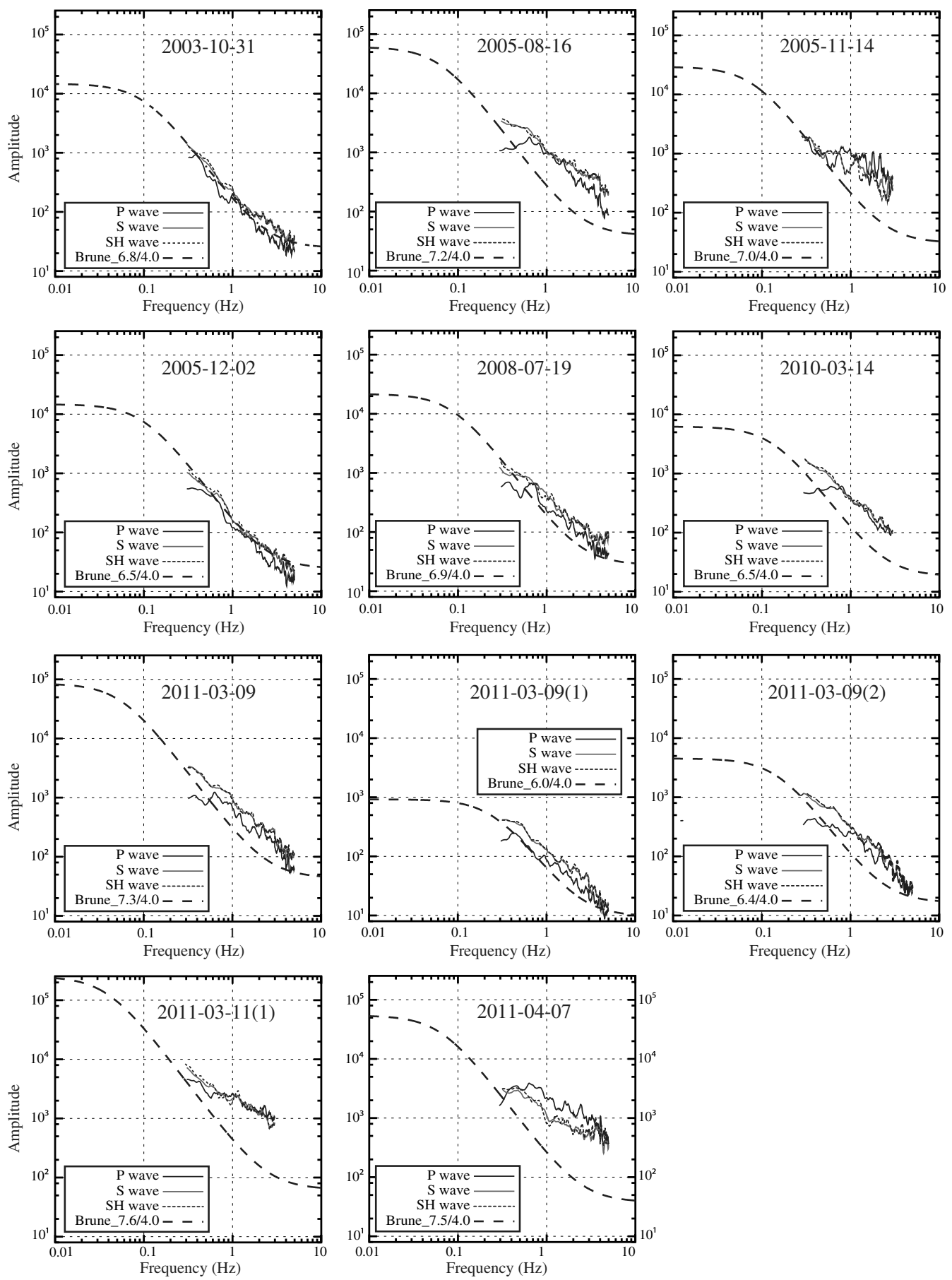

Figure 8. Average $P, S$, and $S H$ source spectra for the large events around the Tohoku megathrust determined using the EGF method, with a nominal $M_{\mathrm{w}} 4.0$ reference event. The dashed curves show the spectral ratio relative to an $M_{\mathrm{w}} 4.0$ event for the reference Brune $\omega^{-2}$ source models with parameters as in Figure 7. The source spectra are valid from about 0.3 to $3.0 \mathrm{~Hz}$, and all are above the expected corner frequency of the large event; the flattening of the spectra below $0.3 \mathrm{~Hz}$ is not to be inferred as a corner frequency effect. Some of the EGF events are smaller than $M_{\mathrm{w}} 4.0$, so the estimated source spectra do not all flatten at $2 \mathrm{~Hz}$ as expected for the reference model.

\section{Far-Field $P$-Wave Spectral Analysis}

To provide a connection between the regional spectral analysis and teleseismic observations, we calculated the average far-field $P$-wave spectra for four large events around the megathrust fault offshore of Honshu, as shown in Figure 11. The observed far-field $P$-wave spectra are estimated at frequencies less than $\sim 0.05 \mathrm{~Hz}$ using finite-fault models inverted directly from teleseismic body-wave observations and at frequencies greater than $\sim 0.05 \mathrm{~Hz}$ from broadband teleseismic $P$-wave spectra. Reference source spectra for the Brune $\omega^{-2}$ model with 3-MPa stress drop are shown in each case. The observed spectra have systematic variations in high-frequency slope in the passband 

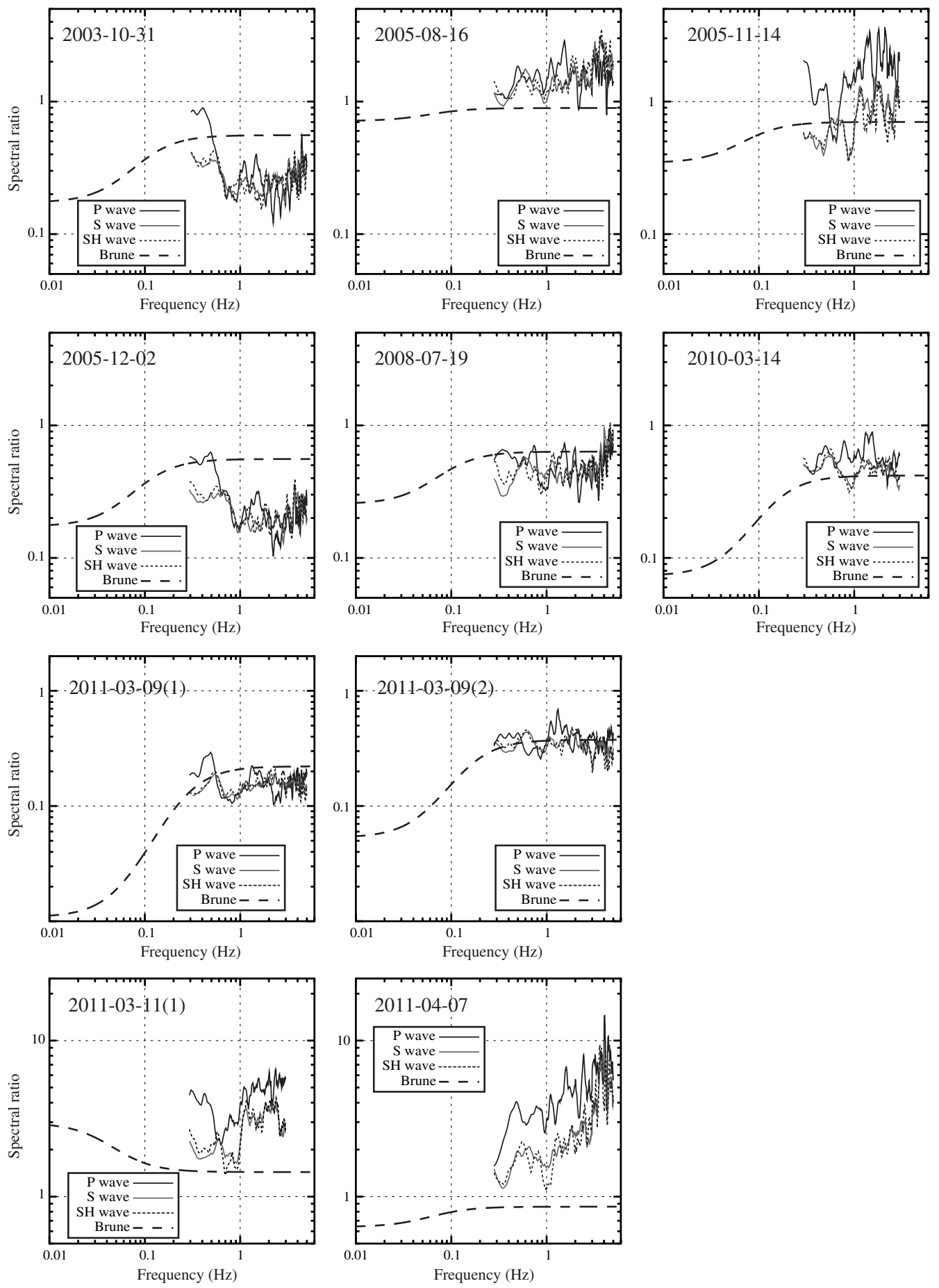

Figure 9. The spectral ratios of $P, S$, and $S H$ EGF-corrected source spectra relative to the foreshock (event 2011-03-09). The dashed curves show the spectral ratios for the reference 3-MPa Brune $\omega^{-2}$ source models. The spectral ratios are valid from about $0.3 \mathrm{~Hz}$ to $3.0 \mathrm{~Hz}$.

around $0.1-1 \mathrm{~Hz}$, with event 2005-08-16 in domain $\mathrm{C}$ and intraslab thrust event 2011-04-07 having relative enrichment of spectral amplitudes above $\sim 0.3 \mathrm{~Hz}$, the foreshock (201103-09) in domain B having lower spectral amplitudes above $\sim 0.02 \mathrm{~Hz}$, and the 2011-03-11 Tohoku mainshock, which ruptured domains $\mathrm{A}, \mathrm{B}$, and $\mathrm{C}$, showing spectral amplitudes comparable to the reference source spectrum. In this case, we are estimating the full bandwidth of the spectra, establishing the corner frequency and moment level of the spectra, which we cannot achieve with the EGF method using the regional data due to the bandwidth constraints. For the corresponding resolved portions of the source spectra, from 0.3 to $1.0 \mathrm{~Hz}$, the regional and teleseismic spectral variations are very consistent. For example, the ratio of the 2005-08-16 spectra to 
(a)

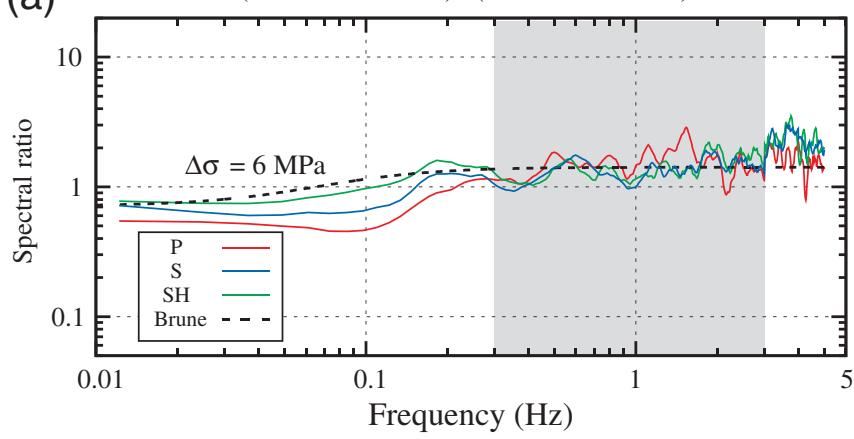

(c)

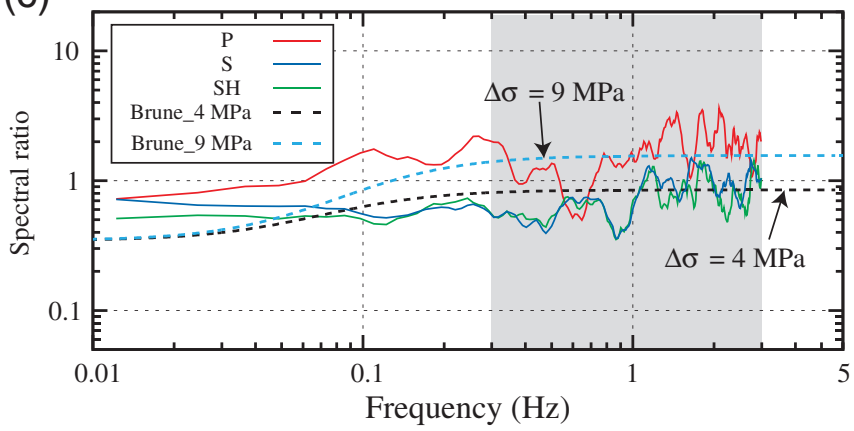

(e)

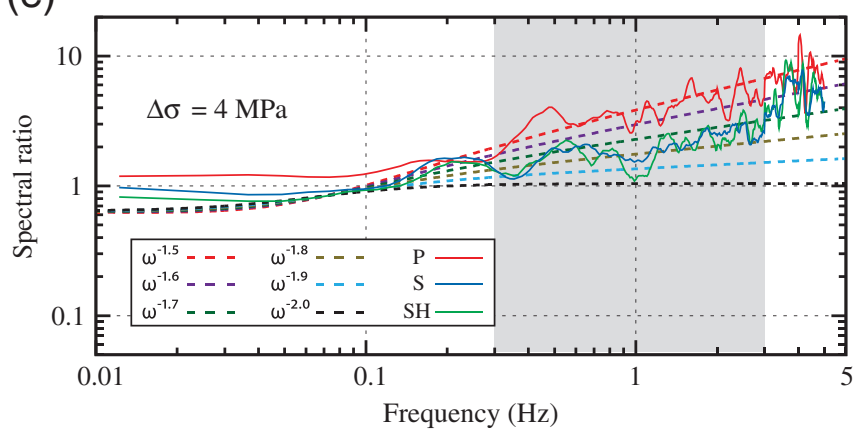

(b)
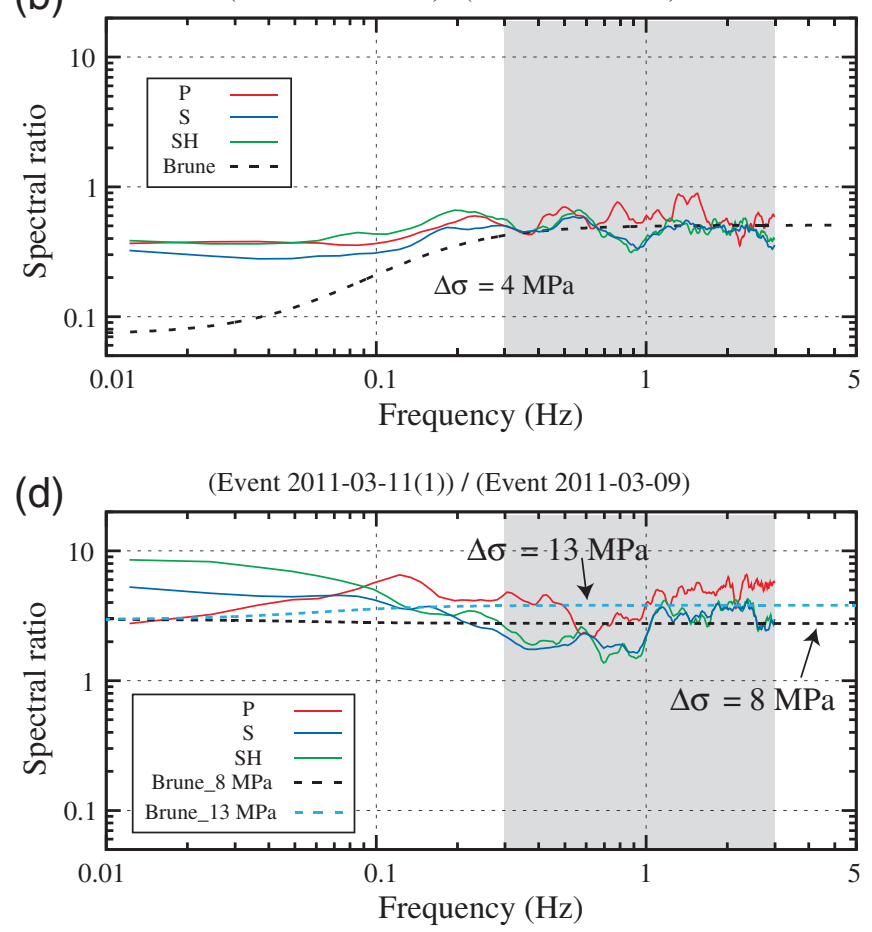

(f)

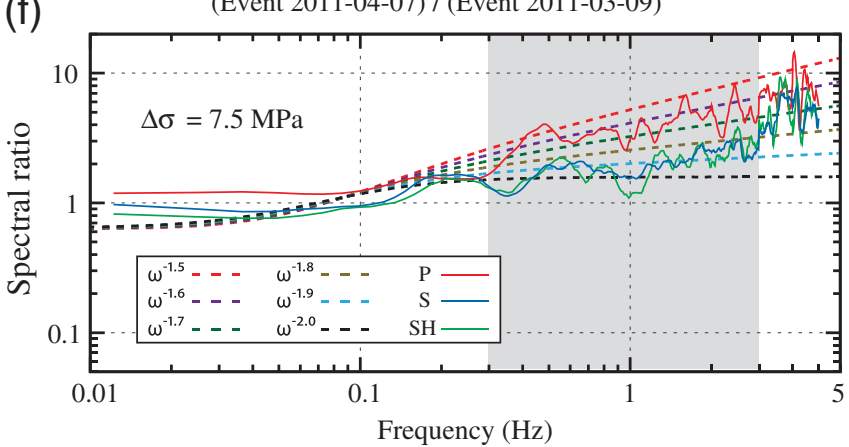

Figure 10. Estimation of relative stress drops for the domain C events (a) 2005-08-16 and (b) 2010-03-14, (c) outer-rise normal-faulting events 2005-11-14 and (d) 2011-03-11(1), and the intraslab compressional event 2011-04-07 (e and f) based on the spectral ratios from Figure 9. The reference (denominator) is the 2011-03-09 foreshock, for which we assume a stress drop of 3 MPa and an $\omega^{-2}$ source model. Dashed lines in (a)-(d) indicate the spectral ratios predicted by $\omega^{-2}$ source models with the indicated stress drop for the numerator event, which provide a good fit on the observed spectral ratios relative to the constant 3 MPa results in Figure 9. The set of dashed lines in (e) and (f) are the spectral ratios predicted by $\omega^{-n}$ models for the numerator event with the value of $n$ ranging from 1.5 to 2.0 for stress drops of 4 and 7.5 MPa, respectively. The $n \sim 1.6$ and $\sim 1.8$ with stress drop 7.5 MPa provide a good fit on the spectral ratios of 2011-04-07 relative to the event 2011-03-09 for $P$ wave and $S / S H$ wave, respectively. The shaded regions show the frequency band in which the spectral ratios are valid from the EGF method.

the foreshock spectra is about 2 over the entire passband, which agrees very well with the ratio for $P$ energy in Figure 9. Similarly, the teleseismic $P$-wave ratio for the 2011-04-07 event relative to the foreshock increases with frequency (up to $2 \mathrm{~Hz}$ in this case) by about the same amount as in the regional ratio in Figure 9. This consistency indicates that the teleseismic spectral estimates provide robust relative spectral behavior up to $1-2 \mathrm{~Hz}$, which is encouraging for future analysis of larger numbers of events, as it is not necessary to use EGF deconvolution to suppress average attenuation variations because they appear to be minor (although slab effects may cause differential effects for some paths).
There is still a direct dependence on the attenuation correction used in the analysis, but that is likely to at least be uniform for nearby events. The consistency also reinforces the interpretation of depth-varying source radiation properties along the megathrust and the high-frequency enrichment of seismic waves from intraslab events.

\section{Discussion and Conclusions}

Observed variations in seismic wave radiation from different portions of megathrust faults motivated this investigation of ground motion and source spectra for earthquakes 
(a)

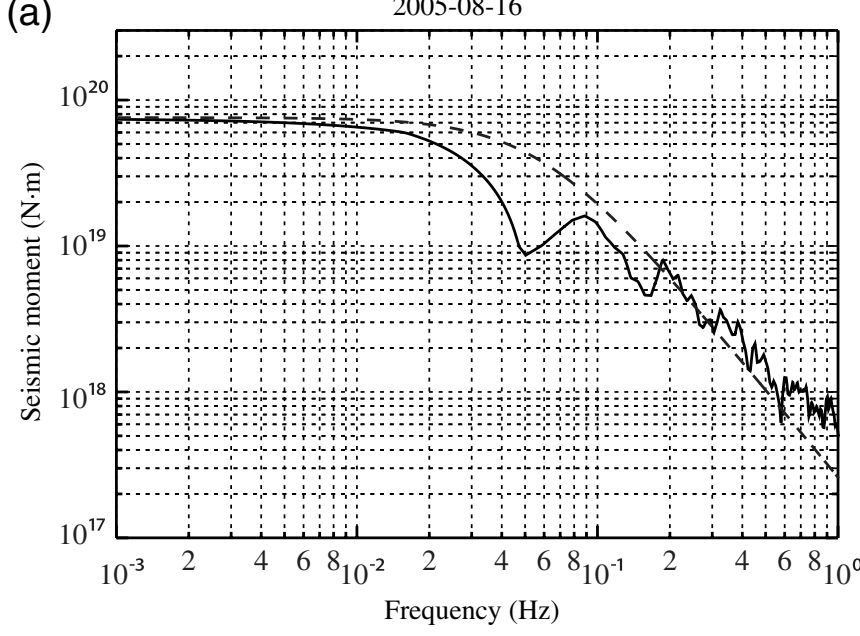

(c)

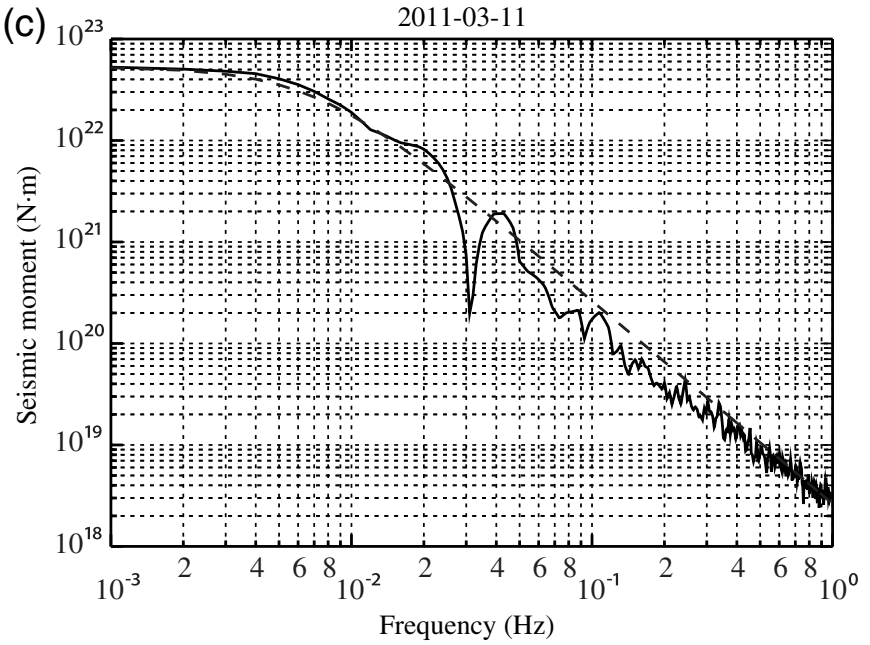

(b)

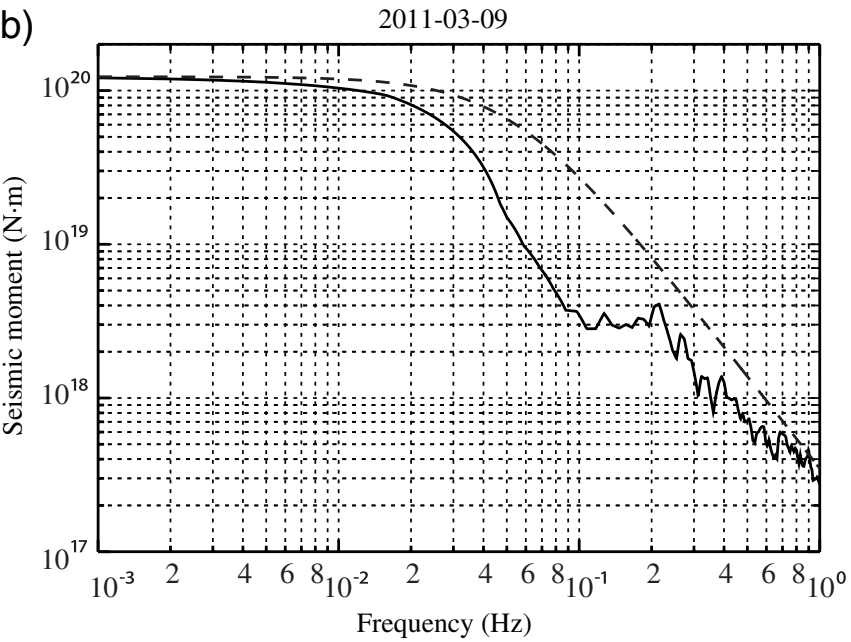

(d)

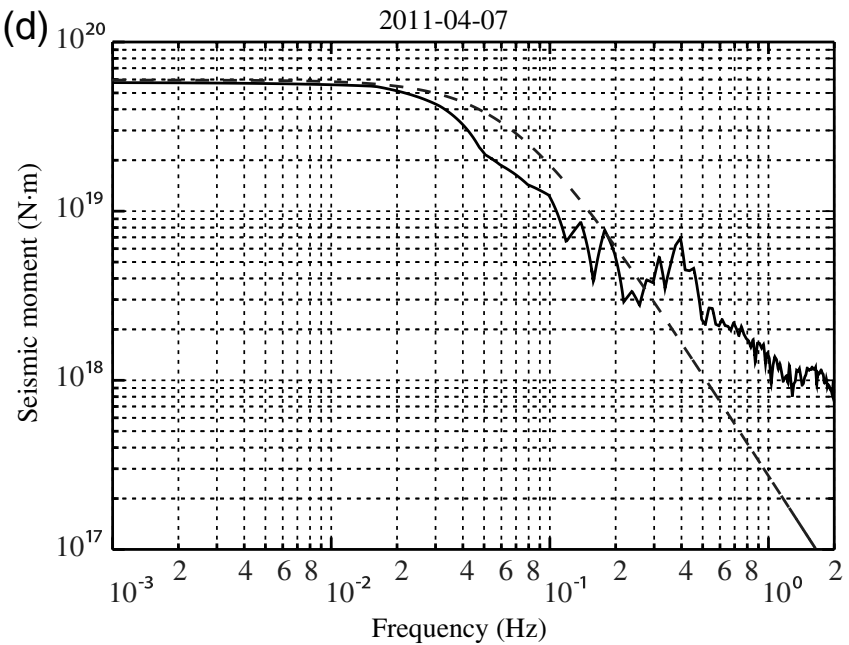

Figure 11. The stacked source spectra for far-field $P$ waves for large events around the Tohoku megathrust. In each panel, the solid black line indicates the observed spectra, estimated at frequencies less than $\sim 0.05 \mathrm{~Hz}$ using finite-fault models inverted from teleseismic bodywave observations and at frequencies higher than $\sim 0.05 \mathrm{~Hz}$ calculated directly from broadband teleseismic $P$ waves. The dashed lines are reference source spectra for the Brune $\omega^{-2}$ model with 3-MPa stress drop and the GCMT seismic moments.

around the rupture zone of the 2011 Tohoku earthquake. The results build upon many prior observations indicating (1) strength of ground motion generally decreases as source location moves farther offshore, (2) intraplate events tend to have higher apparent corner frequencies in general, and (3) sources deviate from constant stress-drop behavior even on a single fault. The main contribution here is the quantitative resolution of source spectra (for at least portions of the high-frequency range) to supplement qualitative indicators such as backprojection of teleseismic short-period $P$ waves. We clarify how energy release can vary over the megathrust and in the proximate intraslab environment.

Figure 12a shows the cross section modified from the megathrust domain figure of Lay et al. (2012, their fig. 6), adding two intraslab environments, region (1) in the outertrench slope and region (2) below the leading edge of the seismogenic portion of the megathrust, together with a list of the events we studied. Only one of our events, 2011-03-09 (1), possibly locates in domain A, for the JMA location. This event is uncertain in placement (the GCMT location places it in domain B). We do not yet have a clear isolated large tsunami earthquake in the Tohoku region similar to the 1896 event to the north, but the mainshock appears to have ruptured all the way through domain A to the trench, with shallow rupture attributes being consistent with a tsunami earthquake.

Figure $12 \mathrm{~b}$ illustrates the spectral amplitudes for each of the megathrust domains and intraplate regions taken from the actual spectra shown in Figure 9. All of the megathrust events have similar spectral decay rates, but the domain $\mathrm{C}$ events have higher amplitude due to the higher corner frequency for a given moment. The intraplate events have lower decay rates and higher spectral amplitudes, indicating both higher stress drop and distinct high-frequency spectral fall-off.

Figure 12c shows the EGF-corrected source spectral ratios from Hi-net data (Fig. 9) at $3 \mathrm{~Hz}$ relative to the foreshock (2011-03-09) as a function of distance from the trench (the JMA locations are used). The $3-\mathrm{Hz}$ amplitudes (adjusted relative to the 3-MPa constant stress drop reference spectrum as 

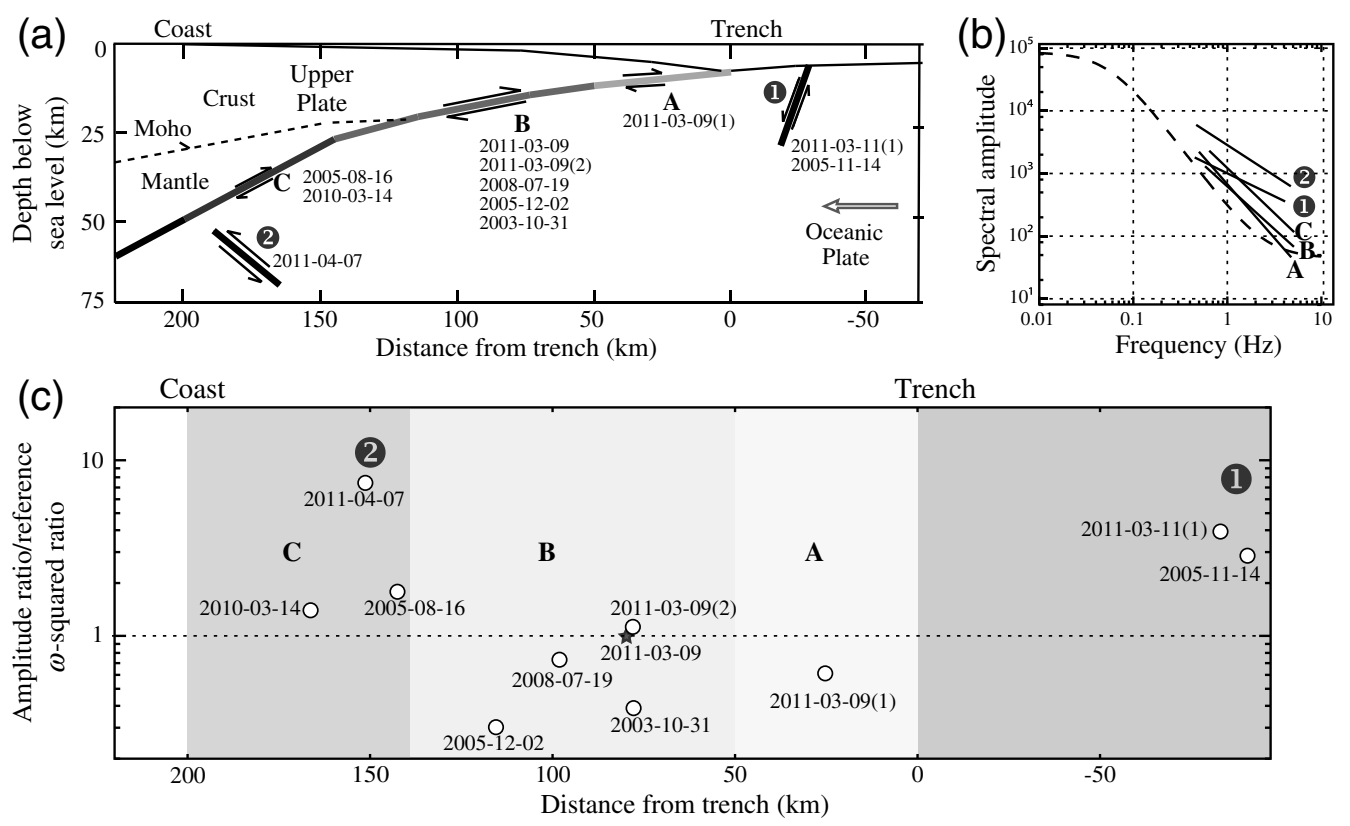

Figure 12. (a) Schematic cross section around the Tohoku megathrust with five environments of distinct source spectral characteristics: domains A, B, and C located on the megathrust and intraplate regions (1) and (2) in the Pacific plate. The dashed line in (b) shows the spectral ratio of event 2011-03-09 relative to an $M_{\mathrm{w}} 4.0$ event for the reference Brune $\omega^{-2}$ source models with 3-MPa stress drop and the regional CMT seismic moments, and the solid lines are a linear approximation of averaged source spectra of events 2011-03-11(1) in region (1), 2011-03-09 (1) in domain A, 2011-03-09 in domain B, 2005-08-16 in domain C, and 2011-04-07 in region (2), scaling by the corresponding expected spectra for Brune $\omega^{-2}$ source models. (c) The 3-Hz amplitude ratio of the EGF-corrected source spectra relative to foreshock 2011-03-09 is normalized by spectral ratios for the Brune $\omega^{-2}$ source models with regional CMT seismic moment and plotted as a function of perpendicular distance from the trench to the JMA source locations. The star shows the location of the foreshock 2011-03-09 with relative spectral ratio of 1.

in Fig. 4) are large for the domain $\mathrm{C}$ and region (1) and (2) events. These EGF-corrected ratios should represent rupture physics effects isolated from propagation effects, whereas Figure 4 represents ground shaking variations that have both source and propagation contributions.

Overall, the behavior of large earthquake sources around the Tohoku rupture indicates that, for a given magnitude, the greatest shaking hazard is associated with the events near the coast, not just due to proximity to the land, but also because the events have higher spectral amplitudes at short period and higher $Q$ along the path from the source to the site. It is advisable to treat the deep megathrust and down-dip intraslab events distinctly from other shallow earthquakes in groundmotion predictions.

The variations in source spectra reflect the variations in basic source physics; the model of depth-dependent source radiation advanced by Lay et al. (2012) is supported by the results of the large events that rupture in domains $\mathrm{B}$ and $\mathrm{C}$. More sampling of domain A is needed to establish the characteristics of domain A events, but the characteristics of tsunami earthquakes elsewhere, including the 1896 Sanriku event to the north, are now well established (Polet and Kanamori, 2000; Lay and Bilek, 2007; Convers and Newman, 2011). The favorable comparison between carefully measured teleseismic spectra and regional EGF-corrected source spectra indicates that the source variations can be reliably isolated with full spectral amplitude determinations.
This is an important supplement to procedures such as backprojection, which view the short-period wave field through the lens of a strong coherency filter that does not necessarily reflect the absolute (or even relative) spectral levels. In combination, these methods are unveiling the systematic spatialand mechanism-dependent variations in source radiation that can guide both ground-shaking hazard analysis and further fundamental studies on the causes of stress drop and spectral decay rate variations.

\section{Data and Resources}

Seismograms used in this study included regional strong ground motion recordings from K-NET and KiK-net stations and short-period recordings from the NIED Hi-net stations by and broadband teleseismic $P$-wave data from Incorporated Research Institutions for Seismology (IRIS) Data Management System (DMS) (http://www.iris.edu; last accessed March 2012). Data from KiK-net, K-NET, and Hi-net can be obtained from http://www.kik.bosai.go.jp, http://www.k -net.bosai.go.jp, and http://www.hinet.bosai.go.jp (last accessed March 2012). The Global Centroid Moment Tensor (GCMT) catalog can be obtained from http://www .globalcmt.org/CMTsearch.html (last accessed March 2012). K. Katsumata provided the JMA-unified catalog (K. Katsumata, personal comm., 2011), and Y. Asano provided the regional CMT solutions (Y. Asano et al., personal comm., 2011). Some plots were made using the Generic 
Mapping Tools (http://www.soest.hawaii.edu/gmt; Wessel and Smith, 1998), and some data processing utilized Seismic Analysis Code (SAC) software (http://www.iris.edu/software/ sac/manual.html, last accessed March 2012).

\section{Acknowledgments}

This work made use of Generic Mapping Tools (GMT) and Seismic Analysis Code (SAC) software and Federation of Digital Seismic Networks (FDSN) seismic data. The Incorporated Research Institutions for Seismology Data Management System (IRIS-DMS) provided the teleseismic $P$-wave data, and the F-net, K-NET, KiK-net, and Hi-net data were obtained from the National Research Institute for Earth Science and Disaster Prevention (NIED) data centers. We thank Y. Asano for sharing his catalog of redetermined regional CMT solutions with us. We thank an anonymous reviewer and J. Anderson for thoughtful comments that improved the manuscript. This work was supported by NSF Grant EAR0635570.

\section{References}

Allmann, B. P., and P. M. Shearer (2009). Global variations of stress drop for moderate to large earthquakes, J. Geophys. Res. 114, no. B01310, doi: 10.1029/2008JB005821.

Ammon, C. J., H. Kanamori, and T. Lay (2008). A great earthquake doublet and seismic stress transfer cycles in the Central Kuril Islands, Nature 451, 561-565.

Ammon, C. J., T. Lay, H. Kanamori, and M. Cleveland (2011). A rupture model of the 2011 Off the Pacific Coast of Tohoku earthquake, Earth Planets Space 63, 693-696, doi: 10.5047/eps.2011.05.015.

Asano, Y., T. Saito, Y. Ito, K. Shiomi, H. Hirose, T. Matsumoto, S. Aoi, S. Hori, and S. Sekiguchi (2011). Spatial distribution and focal mechanisms of aftershocks of the 2011 Off the Pacific Coast of Tohoku earthquake, Earth Planets Space 63, 669-673.

Assimaki, D., W. Li, J. Steidl, and K. Tsuda (2008). Site amplification and attenuation via downhole array inversion: A comparative study of the 2003 Miyagi-Oki aftershock sequence, Bull. Seismol. Soc. Am. 98, no. 1, 301-330, doi: 10.1785/0120070030.

Bilek, S. L., and T. Lay (1998). Variation of interplate fault zone properties with depth in the Japan subduction zone, Science 281, 1175-1178.

Bilek, S. L., H. R. DeShon, and E. R. Engdahl (2012). Spatial variations in earthquake source characteristics within the $2011 M_{\mathrm{w}}=9.0$ Tohoku, Japan rupture zone, Geophys. Res. Lett 39, L09304, doi: 10.1029/ 2012GL051399.

Boore, D. M. (1983). Stochastic simulation of high-frequency ground motions based on seismological models of the radiated spectra, Bull. Seismol. Soc. Am. 73, 1865-1894.

Brune, J. (1970). Tectonic stress and the spectra of seismic shear waves from earthquakes, J. Geophys. Res. 75, 4997-5009, doi: 10.1029/ JB075i026p04997.

Christensen, D. H., and L. J. Ruff (1988). Seismic coupling and outer-rise earthquakes, J. Geophys. Res. 93, 13,421-13,444.

Convers, J. A., and A. V. Newman (2011). Global evaluation of large earthquake energy from 1997 through mid-2010, J. Geophys. Res. 116, B08304, doi: 10.1029/2010JB007928.

Fujii, Y., K. Satake, S. Sakai, M. Shinohara, and T. Kanazawa (2011). Tsunami source of the 2011 Off the Pacific Coast of Tohoku, Japan, earthquake, Earth Planets Space 63, no. 7, 815-820, doi: 10.5047/ eps.2011.06.010.

Hayes, G. (2011). Rapid source characterization of the 03-11-2011 $M_{\mathrm{w}} 9.0$ Off the Pacific Coast of Tohoku earthquake, Earth Planets Space 63, 529-534, doi: 10.5047/eps.2011.05.012.

Hino, R., R. Azuma, Y. Ito, Y. Yamamoto, K. Suzuki, H. Tsushima, S. Suzuki, M. Miyashita, T. Tomori, M. Arizono, and G. Tange (2009). Insight into complex rupturing of the immature bending normal fault in the outer slope of the Japan trench from aftershocks of the 2005 Sanriku earthquake $\left(M_{\mathrm{w}}=7.0\right)$ located by ocean bottom seismometry, Geochem. Geophys. Geosys, 10, Q07018, doi: 10.1029/ 2009GC002415.

Ide, S., A. Baltay, and G. C. Beroza (2011). Shallow dynamic overshoot and energetic deep rupture in the $2011 M_{\mathrm{w}} 9.0$ Tohoku-Oki earthquake, Science 33, 1426-1429.

Iinuma, T., M. Ohzono, Y. Ohta, and S. Miura (2011). Coseismic slip distribution of the 2011 Off the Pacific Coast of Tohoku earthquake (M 9.0) estimated based on GPS data-Was the asperity in MiyagiOki ruptured? Earth Planets Space 63, 643-648.

Irikura, K. (1986). Prediction of strong acceleration motions using empirical Green's function, in Proc. of the 7th Japan Earthquake Engineering Symposium, Tokyo, Japan, 10-12 December 1986, $127-132$.

Ishii, M. (2011). High-frequency rupture properties of the $M_{\mathrm{w}} 9.0$ Off the Pacific Coast of Tohoku earthquake, Earth Planets Space 63, 609-614, doi: 10.5047/eps.2011.07.009.

Ito, Y., T. Tsuji, Y. Osada, M. Kido, D. Inazu, Y. Hayashi, H. Tsushima, R. Hino, and H. Fujimoto (2011). Frontal wedge deformation near the source region of the 2011 Tohoku-Oki earthquake, Geophys. Res. Lett. 38, L00G05, doi: 10.1029/2011GL048355.

Iwata, T., and K. Asano (2011). Characterization of the heterogeneous source model of intraslab earthquakes toward strong ground motion prediction, Pure Appl. Geophys. 168, 117-124.

Kanamori, H. (1971). Seismological evidence for a lithospheric normal faulting-The Sanriku earthquake of 1933, Phys. Earth Planet. In. 4, 289-300.

Kanamori, H. (1972). Mechanism of tsunami earthquakes, Phys. Earth Planet. In. 6, 246-259.

Kanamori, H., W. H. K. Lee, and K.-F. Ma (2012). The 1909 Taipei earthquake-implication for seismic hazard in Taipei, Geophys. J. Int. 191, 126-146, doi: 10.1111/j.1365-246X.2012.05589.x.

Koketsu, K., Y. Yokota, N. Nishimura, Y. Yagi, S. Miyazaki, K. Satake, Y. Fujii, H. Miyake, S. Sakai, Y. Yamanaka, and T. Okada (2011). A unified source model for the 2011 Tohoku earthquake, Earth Planet. Sci. Lett. 310, 480-487, doi: 10.1016/j.eps1.2011.09.009.

Koper, K. D., A. R. Hutko, and T. Lay (2011). Along-dip variation of teleseismic short-period radiation from the 11 March 2011 Tohoku earthquake ( $M_{\mathrm{w}}$ 9.0), Geophys. Res. Lett. 38, L21309, doi: 10.1029/2011GL049689.

Koper, K. D., A. R. Hutko, T. Lay, C. J. Ammon, and H. Kanamori (2011). Frequency-dependent rupture process of the $2011 M_{\mathrm{w}} 9.0$ Tohoku earthquake: Comparison of short-period $P$-wave back-projection images and broadband seismic rupture models, Earth Planets Space 63, 599-602, doi: 10.5047/eps.2011.05.026.

Kurahashi, S., and K. Irikura (2011). Source model for generating strong ground motions during the 2011 Off the Pacific Coast of Tohoku earthquake, Earth Planets Space 63, 571-576, doi: 10.5047/ eps.2011.06.044.

Lay, T., and S. Bilek (2007). Anomalous earthquake ruptures at shallow depths on subduction zone megathrusts, in The Seismogenic Zone of Subduction Thrust Faults, T. H. Dixon and J. C. Moore (Editors), Columbia University Press, New York, 476-511.

Lay, T., C. J. Ammon, H. Kanamori, M. J. Kim, and L. Xue (2011). Outer trench-slope faulting and the $2011 M_{\mathrm{w}} 9.0$ Off the Pacific Coast of Tohoku earthquake, Earth Planets Space 63, no. 7, 713-718, doi: 10.5047/eps.2011.05.006.

Lay, T., C. J. Ammon, H. Kanamori, L. Xue, and M. J. Kim (2011). Possible large near-trench slip during the $2011 M_{\mathrm{w}} 9.0$ Off the Pacific Coast of Tohoku earthquake, Earth Planets Space 63, 687-692, doi: 10.5047/ eps.2011.05.033.

Lay, T., L. Astiz, H. Kanamori, and D. H. Christensen (1989). Temporal variation of large intraplate earthquakes in coupled subduction zones, Phys. Earth Planet. In. 54, 258-312.

Lay, T., H. Kanamori, C. J. Ammon, K. D. Koper, A. R. Hutko, L. Ye, H. Yue, and T. M. Rushing (2012). Depth-varying rupture properties of subduction zone megathrust faults, J. Geophys. Res. 117, B04311, doi: 10.1029/2011JB009133. 
Lee, S.-J., B.-S. Huang, M. Ando, H.-C. Chiu, and J.-H. Wang (2011) Evidence of large scale repeating slip during the 2011 Tohoku-Oki earthquake, Geophys. Res. Lett. 38, L19306, doi: 10.1029/ 2011GL049580.

Madariaga, R. (1976). Dynamics of an expanding circular fault, Bull. Seismol. Soc. Am. 66, 639-666.

Maeda, T., T. Furumura, S. Sakai, and M. Shinohara (2011). Significant tsunami observed at ocean-bottom pressure gauges during the 2011 Off the Pacific Coast of Tohoku earthquake, Earth Planets Space 63, 803-808, doi: 10.5047/eps.2011.06.005.

Meng, L., A. Inbal, and J.-P. Ampuero (2011). A window into the complexity of the dynamic rupture of the $2011 M_{\mathrm{w}} 9$ Tohoku-Oki earthquake, Geophys. Res. Lett. 38, L00G07, doi: 10.1029/2011GL048118.

Miyatake, T., Y. Yagi, and T. Yasuda (2004). The dynamic rupture process of the 2001 Geiyo, Japan, earthquake, Geophys. Res. Lett. 31, L12612, doi: 10.1029/2004GL019721.

Morikawa, N., and T. Sasatani (2003). Source spectral characteristics of two large intra-slab earthquakes along the southern Kurile-Hokkaido arc, Phys. Earth Planet. In. 137, 67-80.

Morikawa, N., and T. Sasatani (2004). Source models of two large intraslab earthquakes from broadband strong ground motions, Bull. Seismol. Soc. Am. 94, 803-817.

Nakajima, J., A. Hasegawa, and S. Kita (2011). Seismic evidence for reactivation of a buried hydrated fault in the Pacific slab by the 2011 M 9.0 Tohoku earthquake, Geophys. Res. Lett. 38, L00G06, doi: 10.1029/ 2011GL048432.

Ohta, Y., S. Miura, M. Ohzono, S. Kita, T. Iinuma, T. Demachi, K. Tachibana, T. Nakayama, S. Hirahara, S. Suzuki, T. Sato, N. Uchida, A. Hasegawa, and N. Umino (2011). Large intraslab earthquake (2011 April 7, $M$ 7.1) after the 2011 Off the Pacific Coast of Tohoku earthquake ( $M$ 9.0): Coseismic fault model based on the dense GPS network data, Earth Planets Space 63, 1207-1211.

Ozawa, S., T. Nishimura, H. Suito, T. Kobayahi, M. Tobita, and T. Imakiire (2011). Coseismic and postseismic slip of the 2011 magnitude-9 Tohoku-Oki earthquake, Nature 475, 373-376, doi: 10.1038/ nature10227.

Polet, J., and H. Kanamori (2000). Shallow subduction zone earthquakes and their tsunamigenic potential, Geophys. J. Int. 142, 684-702.

Pollitz, F., R. Bürgmann, and P. Banerjee (2011). Geodetic slip model of the 2011 M 9.0 Tohoku earthquake, Geophys. Res. Lett. 38, L00G08, doi: 10.1029/2011GL048632.

Purvance, M. D., and J. G. Anderson (2003). A comprehensive study of the observed spectral decay in strong-motion accelerations recorded in Guerrero, Mexico, Bull. Seismol. Soc. Am. 93, no. 2, 600-611, doi: $10.1785 / 0120020065$.

Shao, G., X. Li, C. Ji, and T. Maeda (2011). Focal mechanism and slip history of the $2011 M_{\mathrm{w}} 9.1$ Off the Pacific Coast of Tohoku earthquake, constrained with teleseismic body and surface waves, Earth Planets Space 63, 559-564, doi: 10.5047/eps.2011.06.028.

$\mathrm{Si}, \mathrm{H}$., and S. Midorikawa (1999). New attenuation relations for peak ground acceleration and velocity considering effects of fault type and site condition, J. Struct. Constr. Eng., AIJ 523, 63-70.

Simons, M., S. E. Minson, A. Sladen, F. Ortega, J. Jiang, S. E. Owen, L. Meng, J. Ampuero, S. Wei, R. Chu, D. V. Helmberger, H. Kanamori, E. Hetland, A. W. Moore, and F. H. Webb (2011). The 2011 magnitude 9.0 Tohoku-Oki earthquake: Mosaicking the megathrust from seconds to centuries, Science 332, 1421-1425.
Suzuki, W., S. Aoi, and H. Sekiguchi (2009). Rupture process of the 2008 northern Iwate intraslab earthquake derived from strong-motion records, Bull. Seismol. Soc. Am. 99, 2825-2835, doi: 10.1785/ 0120080331.

Tsuda, K., J. Steidl, R. Archuleta, and D. Assimaki (2006). Site-response estimation for the 2003 Miyagi-Oki earthquake sequence considering nonlinear site response, Bull. Seismol. Soc. Am. 96, 1474-1482, doi: $10.1785 / 0120050160$.

Wang, D., and J. Mori (2011). Rupture process of the 2011 Off the Pacific Coast of Tohoku earthquake $\left(M_{\mathrm{w}} 9.0\right)$ as imaged with back-projection of teleseismic $P$ waves, Earth Planets Space 63, 603-607, doi: 10.5047/eps.2011.05.029.

Wessel, P., and W. H. F. Smith (1998). New, improved version of the Generic Mapping Tools released, Eos Trans. AGU, 79, 579.

Yagi, Y., and Y. Fukahata (2011). Rupture process of the 2011 Tohoku-Oki earthquake and absolute elastic strain release, Geophys. Res. Lett. 38, L19307, doi: 10.1029/2011GL048701.

Yamazaki, Y., T. Lay, K. F. Cheung, H. Yue, and H. Kanamori (2011). Modeling near-field tsunami observations to improve finite-fault slip models for the 11 March 2011 Tohoku earthquake, Geophys. Res. Lett. 38, L00G15, doi: 10.1029/2011GL049130.

Yao, H., P. Gerstoft, P. M. Shearer, and C. Mecklenbrauker (2011). Compressive sensing of the Tohuku-Oki $M_{\mathrm{w}} 9.0$ earthquake: Frequencydependent rupture modes, Geophys. Res. Lett. 38, doi: 10.1029/ 2011 GL049223.

Yokota, Y., K. Koketsu, Y. Fujii, K. Satake, S. Sakai, M. Shinohara, and T. Kanazawa (2011). Joint inversion of strong motion, teleseismic, geodetic, and tsunami datasets for the rupture process of the 2011 Tohoku earthquake, Geophys. Res. Lett. 38, L00G21, doi: 10.1029/ 2011 GL050098.

Yoshida, Y., H. Ueno, D. Muto, and S. Aoki (2011). Source process of the 2011 Off the Pacific Coast of Tohoku earthquake with the combination of teleseismic and strong motion data, Earth Planets Space 63, no. 7, 565-569, doi: 10.5047/eps.2011.05.011.

Youngs, R., S. J. Chiou, W. J. Silva, and J. R. Humphrey (1997). Strong ground motion attenuation relationships for subduction zone earthquakes, Seismol. Res. Lett. 68, no. 1, 58-73.

Yue, H., and T. Lay (2011). Inversion of high-rate (1-sps) GPS data for rupture process of the 11 March 2011 Tohoku earthquake $\left(M_{\mathrm{w}} 9.1\right)$, Geophys. Res. Lett. 38, L00G09, doi: 10.1029/2011GL048700.

Zhao, D., Z. Huang, N. Umino, A. Hasegawa, and H. Kanamori (2011). Structural heterogeneity in the megathrust zone and mechanism of the 2011 Tohoku-oki earthquake ( $M_{\mathrm{w}}$ 9.0), Geophys. Res. Lett. 38, L17308, doi: 10.1029/2011GL048408.

Department of Earth and Planetary Sciences

University of California Santa Cruz

Santa Cruz, California 95064

(L.Y., T.L.)

Seismological Laboratory

California Institute of Technology

Pasadena, California 91125

(H.K.)

Manuscript received 30 March 2012 